\title{
The Moray Eels of Australia and New Zealand, with the Description of Two New Species (Anguilliformes: Muraenidae)
}

\author{
Eugenia B. BÖHLKE ${ }^{1 \dagger}$ AND JOHN E. MCCOSKER ${ }^{2}$ \\ ${ }^{1}$ Academy of Natural Sciences of Philadelphia, 1900 Benjamin Franklin Parkway, \\ Philadelphia, PA 19103-1195, United States of America \\ ${ }^{2}$ California Academy of Sciences, Golden Gate Park, \\ San Francisco, CA 94118, United States of America \\ jmccosker@calacademy.org
}

\begin{abstract}
Australian and New Zealand moray eel type specimens in museums have been re-examined, their identities established, and brief descriptions of the specimens written. A key to the 59 muraenid species of Australia and New Zealand is presented. Ten species that have remained relatively unknown or inadequately described are redescribed and illustrated: Gymnothorax annasona Whitley, 1937; $G$. atolli (Pietschmann, 1935); G. cribroris Whitley, 1932a; G. longinquus (Whitley, 1948); G. nubilus (Richardson, 1848); G. obesus (Whitley, 1932a); G. porphyreus (Guichenot, 1848); G. prasinus (Richardson, 1848); G. prionodon Ogilby, 1895; and G. woodwardi McCulloch, 1912. A new species from northern Australia is described as G. cephalospilus, and one from southern Australia is described as G. austrinus. New synonymies are proposed: Muraena helena australis Richardson, 1848, and Muraena vorax Ogilby, $1907=$ Muraena helena Linnaeus, 1758; Muraena euptera Günther, $1870=$ Gymnothorax nubilus Richardson, 1848; Muraena tuhua Griffin, 1933, and Gymnothorax griffini Whitley \& Phillipps, 1939 = Gymnothorax obesus (Whitley, 1932a); Gymnothorax maculaepinnis Bleeker, 1866, and Gymnothorax leecote Scott, 1965 = Gymnothorax prasinus (Richardson, 1848); and Muraena mieroszewskii Steindachner, 1896, Gymnothorax leucostigma Jordan \& Richardson, 1909, Gymnothorax nirosus Tanaka, 1918, Muraena shirleyi Griffin, 1933, and Lycodontis wooliensis Whitley, $1968=$ Gymnothorax prionodon Ogilby, 1895. Australian morays considered to be nomena dubia are: Anarchias insuetus Whitley, 1932b; Gymnothorax dakini Whitley \& Colefax, 1938; Gymnothorax garsiae Whitley \& Colefax, 1938; and Gymnothorax scriptus Schneider, 1801. Miscellaneous notes on the changes made to the listing of Australian morays by Paxton et al. (1989), a discussion of the distributions of Australian and New Zealand morays, and an index to all names are provided.
\end{abstract}

BöHlke, Eugenia B., \& John E. McCosKer, 2001. The moray eels of Australia and New Zealand, with the description of two new species (Anguilliformes: Muraenidae). Records of the Australian Museum 53(1): 71-102. 
The moray eels of Australia have not received comprehensive treatment since Weber \& de Beaufort's (1916) review and Munro's (1957) leaflet in the Handbook of Australian Fishes. In their zoological catalogue of Australian fishes, Paxton et al. (1989: 126) introduced the family Muraenidae by stating "There is no comprehensive treatment of the moray eels and the group is badly in need of revision." The fishes inhabiting the shallow tropical waters of northern Australia, including the morays, have been well sampled and are fairly well known inasmuch as many of them are part of the vast tropical fauna of the Indo-Pacific. The ichthyofauna of the cooler waters of sub-tropical and temperate southern Australia and New Zealand is less sampled and less understood. The uncertainty regarding the validity of species described from this area, and the lack of information other than the original descriptions in many cases, indicated study of the type specimens and specimens collected in this area was badly needed. Studies were pursued some years ago by the late Peter H.J. Castle and subsequently by the junior author; recently, we located and re-examined all extant type specimens in the Australian Museum, Sydney, in order to compare them with other muraenid type specimens, most of which have recently been re-examined by the authors. As a result, valid species of Australian and New Zealand waters have been determined, and an updated listing and key to species of the area is now possible.

The family Muraenidae as currently recognised is large and diverse and divided into two subfamilies, externally recognised by the extent of the fins: the Uropterygiinae with dorsal and anal fins restricted to the tail tip, and the Muraeninae with a long dorsal fin beginning near to well before the anus and with anal fin beginning just behind the anus. Fourteen genera are currently recognised: four in the Uropterygiinae (Anarchias, Channomuraena, Scuticaria, and Uropterygius), and ten in the Muraeninae (Echidna, Enchelycore, Enchelynassa, Gymnomuraena, Gymnothorax, Monopenchelys, Muraena, Pseudechidna, Rhinomuraena, and Strophidon). Of these, all but Gymnothorax are characterised by specific, observable external characters, such as the position of the dorsal-fin origin, the length of the tail, the nostril condition, and differences in dentition. However, a great majority of species have been lumped together in Gymnothorax sensu lato (with 14 generic synonyms), because characters used for separation of genera have been found to be invalid or overlapping. Thus, the generic classification used here is based on historical convention and current usage, with many species with widely varying characters all placed in Gymnothorax. That complex genus, as well as the species of Anarchias (we consider our identification of Australian species to be provisional), are in need of revision.

Muraenid species are common and widely distributed, found mainly in tropical waters, with a limited number taken in subtropical or temperate waters. Their abundance and ecological significance is always under-appreciated because of their cryptic behaviour; for example, Brock et al. (1979) used ichthyocides to demonstrate that morays comprised as much as $47 \%$ of the carnivorous fish biomass of a patch reef in Kaneohe Bay, Oahu. A general discussion of the family Muraenidae was published by Böhlke et al. (1989) in their treatment of western Atlantic morays, which included classification, osteology, habitat, behaviour, reproduction, and taxonomic and species characters. More recently, Böhlke et al. (in press) treated the morays of the western central Pacific, and Böhlke \& Randall (2000) reviewed the morays of Hawaii, both publications providing colour and/or black-and-white photographs of many species that are also found in Australian waters. Several recent books dealing with Australian species of fishes are available which, although not comprehensive in treatment, provide accurate identifications and useful colour photographs and paintings of many Australian muraenids. Included are: Randall et al. (1997) on fishes of the Great Barrier Reef; Allen (1992) on fishes of tropical Australia and southeast Asia; Kuiter (1993) on southeastern Australian coastal fishes; Gomon et al. (1994) on fishes of Australia's south coast; and Kuiter's (1997) guide to sea fishes of Australia, directed primarily to divers and fishermen.

A list of the 59 valid species now known to exist in Australian and New Zealand waters, with their common names, is presented in Table 1.A comprehensive key to species, including notes on coloration, vertebral counts, maximum size, and distribution for each species, is presented below. (We have not attempted to diagnose and treat most of the species that appear in the key, rather we have provided for each species a recent and competent literature source or sources that illustrate and describe those species.)

The type specimens of Australian morays in the Australian Museum, Sydney, and other museums were reexamined and additional data taken, including vertebral counts from radiographs. The information obtained has allowed confirmation of the validity of several species and confirmation of the synonymy of others. We lacked an opportunity to locate or examine types of the five species (only one of which is believed to be extant) expected to be in New Zealand museums; however, because the species are closely allied to those in Australian waters, brief summaries of the status of these names are also presented, based on original descriptions and recent information obtained from the late P.H.J. Castle (1999, in litt.). Of the 30 nominal species described from Australia and New Zealand (including the two new species), 11 are here considered valid; 15 have been put in the synonymy of previously described species; and four remain as nomena dubia.

We provide redescriptions of 10 valid species (along with descriptions of their type specimens and their synonyms) found in sub-tropical and temperate waters of the area, which until now have remained relatively unknown or inadequately described, plus descriptions of the two new species. They are: Gymnothorax annasona Whitley, 1937; G. atolli (Pietschmann, 1935); G. austrinus n.sp., G. cephalospilus n.sp., G. cribroris Whitley, 1932a; G. longinquus (Whitley, 1948); G. nubilus (Richardson, 1848); G. obesus (Whitley, 1932a); G. porphyreus (Guichenot, 1848); G. prasinus (Richardson, 1848); G. prionodon, Ogilby, 1895; and G. woodwardi McCulloch, 1912. That section is followed by a complete listing and comments upon the remaining Australian and New Zealand muraenid type specimens.

Several species recently listed by Paxton et al. (1989) in the Zoological Catalogue of Australia are not herein included as part of the Australian-New Zealand fauna; they 
Table 1. Valid species of morays of Australia and New Zealand.

Anarchias allardicei Jordan \& Starks, 1906

Allardice's moray

Anarchias cantonensis (Schultz, 1943)....

Canton Island moray

Anarchias leucurus (Snyder, 1904)

Anarchias seychellensis Smith, 1962

Fine-spotted moray

Echidna nebulosa (Ahl, 1789)

Seychelles moray

Echidna polyzona (Richardson, 1845)

Snowflake moray

Echidna unicolor Schultz, 1953

Barred moray

Enchelycore bayeri (Schultz, 1953) ....

Unicolor moray

Enchelycore ramosa (Griffin, 1926)

Bowmouth moray

Enchelynassa canina (Quoy \& Gaimard, 1824)

Mosaic moray

Gymnomuraena zebra (Shaw, 1797)

Indo-Pacific Viper moray

Gymnothorax annasona Whitley, 1937

Zebra moray

Gymnothorax atolli Pietschmann, 1935

Lord Howe Island moray

Gymnothorax austrinus n.sp.

Atoll moray

Gymnothorax buroensis (Bleeker, 1857)

Southern moray

Gymnothorax castlei Böhlke \& Randall, 1999

Latticetail moray

Gymnothorax cephalospilus n.sp.

Castle's moray

Gymnothorax chilospilus Bleeker, 1865

Head-spot moray

Gymnothorax cribroris Whitley, 1932

Lipspot moray

Gymnothorax enigmaticus McCosker \& Randall, 1982 ...... Enigmatic moray

Gymnothorax eurostus (Abbott, 1861)

Gymnothorax favagineus Bloch \& Schneider, 1801

Indo-Pacific stout moray

Gymnothorax fimbriatus (Bennett, 1832)

Honeycomb moray

Gymnothorax flavimarginatus (Rüppell, 1830)

Darkspotted moray

Gymnothorax fuscomaculatus (Schultz, 1953)

Yellowmargin moray

Gymnothorax gracilicaudus Jenkins, 1903

Brownspotted moray

Gymnothorax intesi (Fourmanoir \& Rivaton, 1979)

Slendertail moray

Gymnothorax javanicus (Bleeker, 1859)

Whitemargin moray

Gymnothorax kidako (Temminck \& Schlegel, 1846)

Giant moray

Gymnothorax longinquus (Whitley, 1948)

Kidako moray

Gymnothorax margaritophorus Bleeker, 1865

Long moray

Gymnothorax mccoskeri Smith \& Böhlke, 1997

Blackpearl moray

Gymnothorax melatremus Schultz, 1953

Gymnothorax meleagris (Shaw, 1795)

Gymnothorax minor (Temminck \& Schlegel, 1848)

McCosker's moray

Dwarf moray

Whitemouth moray

Gymnothorax monochrous Bleeker, 1856

Gymnothorax nubilus (Richardson, 1848)

Gymnothorax nudivomer (Günther, 1867)

Gymnothorax obesus (Whitley, 1932a).

Lesser moray

Monotone moray

Cloudy moray

Gymnothorax pictus (Ahl, 1789)

Yellowmouth moray

Gymnothorax pindae Smith, 1962

Obese moray

Peppered moray

Gymnothorax polyuranodon (Bleeker, 1853)

Gymnothorax porphyreus (Guichenot, 1848)

Pinda moray

Gymnothorax prasinus (Richardson, 1848)

Manytoothed moray

Lowfin moray

Gymnothorax prionodon Ogilby, 1895

Yellow moray

Gymnothorax pseudoherrei Böhlke, 2000

Indo-Pacific spotted moray

Gymnothorax pseudothyrsoideus (Bleeker, 1852b)

False brown moray

Gymnothorax rueppelliae (McClelland, 1844)....

False spotted moray

Gymnothorax thyrsoideus (Richardson, 1845)

Banded moray

Gymnothorax undulatus (Lacepède, 1803)

White-eyed moray

Gymnothorax woodwardi McCulloch, 1912

Gymnothorax zonipectis Seale, 1906

Undulated moray

Rhinomuraena quaesita Garman, 1888

Woodward's moray

Strophidon sathete (Hamilton, 1822)

Bar-tail moray

Uropterygius concolor Rüppell, 1838

Ribbon moray

Uropterygius fuscoguttatus Schultz, 1943 .........

Longtail moray

Unicolor snake moray

Uropterygius marmoratus (Lacepède, 1803)

Brownspotted snake moray

Uropterygius micropterus (Bleeker, 1852)

Marbled snake moray

Uropterygius nagoensis Hatooka, 1984

Nago snake moray 
include names that have been found to be junior synonyms of other species, names considered to be nomena dubia, and/or species incorrectly identified (see under "Miscellaneous remarks" below). We herein add 13 species to their list: Gymnothorax annasona, now considered to be a valid species; G. atolli, a previously unrecognised species from Australia; G. minor (specimens previously identified as $G$. scriptus are this species); G. porphyreus, numerous specimens identified from the area; G. enigmaticus, previously unreported from NE Australia; three recently described species (G. castlei Böhlke \& Randall, 1999; G. mccoskeri Smith \& Böhlke, 1997; and G. pseudoherrei Böhlke, 2000); Anarchias cantonensis and A. leucurus, reported by Randall et al. (1997) from "Great Barrier Reef Waters"; and the two new species.

\section{Methods}

Methods and terminology are as defined in Böhlke (1989). Proportions are expressed in terms of total length (TL), measured from the snout tip to the tip of the tail, or head length (HL), from snout tip to the posterodorsal margin of the gill opening. Preanal length is measured from snout tip to mid-anus; body depth is measured at the gill opening and at the anus and does not include the fins; snout length is measured from snout tip to the anterior margin of the eye; upper-jaw length is from snout tip to the external inner angle of the mouth, lower-jaw length from tip of lower jaw to the external inner angle of the mouth. Head pores are few, with little variation (noted in species accounts only when atypical); morays typically have 3 supraorbital pores ( 1 ethmoid +2 on dorsal snout), 4 infraorbital pores, 6 mandibular pores, and 2 branchial pores. Tooth counts are approximate and include sockets of missing teeth. Vertebral counts are obtained from radiographs as explained in Böhlke (1982); the mean vertebral formula (MVF) is expressed as the mean value for predorsal-preanal-total counts for each species. Institutional abbreviations follow Leviton et al. (1985).

Notes on distribution. We have defined the distribution of all species in the key and text using geographical locations that in some cases coincide with the boundaries of Australian states. The regions that we recognise are not biologically unique but may be useful in a general analysis of reef fish distribution. We define the regions as follows: northeast (NE), from Cape York $\left(15^{\circ} \mathrm{S} 143^{\circ} \mathrm{E}\right)$ to the southeastern border of Queensland; southeast (SE), from northern New South Wales to eastern Victoria; south (S), from the southeastern border of South Australia to Cape Leeuwin $\left(115^{\circ} \mathrm{S} 34^{\circ} \mathrm{E}\right)$, the southwest corner of Western Australia; west (W), from Cape Leeuwin north to the Northwest Cape $\left(22^{\circ} \mathrm{S} 114^{\circ} \mathrm{E}\right)$ of Western Australia; northwest (NW), from the Northwest Cape to the western boundary of Northern Territories; north $(\mathbf{N})$, from the western boundary of Northern Territories to Cape York, Queensland, including the Gulf of Carpentaria.

Cautionary note concerning key: Morays are extremely difficult to identify because many characters show great variability. Proportions, dentition, and coloration may vary due to growth, sexual condition, means and length of preservation, and other factors, thus making the construction and use of a key difficult. The following key should allow identification of "typical" adult specimens, based on dentition and, from couplet 20 on, largely on coloration. Juveniles often exhibit colour patterns that differ considerably from those of the adults. The colour may be distinct and contrasting, changing to become diffuse, dark and/or obscure in large specimens; juveniles often have more and additional rows of teeth, adults may have fewer teeth or lack some entirely, or conversely may have additional rows of teeth. Coloration is not only variable, but also difficult to describe; while some species exhibit distinctive coloration, some do not; what may appear to one person (or in one specimen) as diffuse pale blotches on a dark body may appear to another (or in another specimen) as dark reticulations on a pale body; both possibilities should be pursued when using the key, particularly where additional characters given may aid in identification.

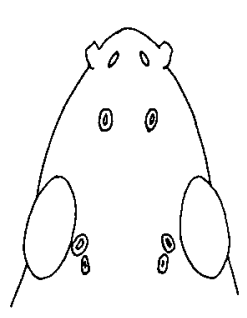

A

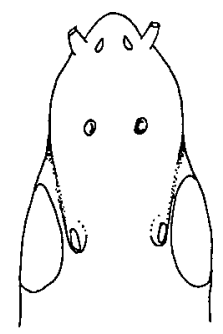

B
Figure 1. A, posterior nostril contiguous with supraorbital pore in all species of Anarchias. B, posterior nostril not contiguous with supraorbital pore, the condition of all species of Uropterygius. 


\section{Key to the species of Moray Eels of Australia and New Zealand}

Abbreviations: TL, total length; $\mathrm{V}$, total vertebrae; MVF, mean vertebral formula. Vertebral numbers may include those from specimens extralimital to Australia and New Zealand. References that provide illustrations and diagnostic characters are indicated in the key by superscript numbers as follows: 1 this study; 2-Allen, 1985; 3-Böhlke, 1997; 4-Böhlke, 2000; 5-Böhlke \& Randall, 1999; 6-Böhlke \& Randall, 2000; 7-Castle \& McCosker, 1986; 8-Kuiter, 1993; 9-McCosker et al., 1984; 10Myers, 1999; 11-Randall et al., 1997; 12-Randall \& Golani, 1995; and 13-Smith \& Böhlke, 1997.

1 Dorsal and anal fins restricted to tail tip; teeth needle-like and pointed subfamily Uropterygiinae ......2

_ Dorsal-fin origin near or before anus; anal-fin origin just behind anus; teeth molariform, rounded, pointed, or caniniform subfamily Muraeninae .... 10

2 Posterior nostril contiguous with an enlarged supraorbital pore, appearing as a double pore (Fig. 1A); adults small, not exceeding $30 \mathrm{~cm}$ Anarchias...... 3

_ Posterior nostril not contiguous with a supraorbital pore (Fig. 1B) most adults small to medium-length, few species exceed $50 \mathrm{~cm}$. Uropterygius. 6

3 Supraorbital pore slightly in advance of centre of eye; body coloration nearly uniform brown, or brown with a network of wide brownish lines, more or less arranged into irregular vertical reticulated bars

_ Supraorbital pore either in line with or slightly behind centre of eye; body coloration either with pale reticulations or pale, stellate blotches

4 Body nearly uniform brown, dorsal fin darker, the tail tip white; head sometimes with a pale bar behind eye, the head pores white; V 97-102; MVF 88-89-99; to $17 \mathrm{~cm}$; W, NW, NE Australia, West Pacific Anarchias allardicei Jordan \& Starks, $1906^{10}$

Body pale, overlain with a network of wide brownish lines arranged into irregular vertical reticulated bars, more obvious posteriorly; underside of head usually pale, the head pores white; V 101-108; MVF 91-93-104; to $20 \mathrm{~cm}$; NE Australia, Indo-Pacific Anarchias cantonensis (Schultz, 1943) $)^{10}$

5 Body varies from nearly uniform brown, through brown mottled with pale brown, to brown with three or four rows of stellate pale blotches; throat pale, the lower jaw often mottled with brown; V 121-132; MVF 111-117-126; to $29 \mathrm{~cm}$; W, NW, SE Australia, widespread in Indo-Pacific from Easter Island to Africa .... Anarchias seychellensis Smith, $1962^{5}$

- Body brown overlain with a faint whitish reticulation on the upper body; chin and throat pale; V 106-112; MVF 98-100-110; to 25 $\mathrm{cm}$; NE Australia, Indo-Pacific to Hawaii Anarchias leucurus (Snyder, 1904) $)^{5}$

6 Body in life and in preservative uniform tan to gray; jaw teeth biserial; V 117-124; MVF 110-114-120; to $32 \mathrm{~cm}$; W, NW Australia, Indo-Pacific Uropterygius concolor Rüppell, $1838^{7,9}$

Body in life and in preservative mottled, spotted, or reticulated; jaw teeth biserial or triserial. 
7 Jaw teeth biserial; body pale to gray, overlain above midline with a reticulated network of fine brown lines; V 113-119; MVF 106-108-117; a small species, to $30 \mathrm{~cm}$; NE Australia, IndoPacific.... Uropterygius micropterus (Bleeker, 1852a) $)^{8,9}$

Jaw teeth triserial; body coloration not as above; may attain a larger size, to $60 \mathrm{~cm}$

8 Coloration of anterior half of body and posterior trunk region notably different; head and chin plain, body uniform brown anteriorly, tail covered by numerous dark brown spots (about equal to eye); V 113-124; MVF 99-104-119; to $30 \mathrm{~cm}$; NE Australia; Indo-Pacific to Hawaii Uropterygius fuscoguttatus Schultz, 19535,10

Coloration of head, trunk and body similar, with either reticulations or indistinct spotting; V 131-144....

9 Mouth large, snout short; body yellow anteriorly, brown posteriorly, overlain with reticulated broad, dark brown lines; V 139-144; MVF 118-124-140; to $71 \mathrm{~cm}$; NE Australia, western Pacific Uropterygius nagoensis Hatooka, 1984, 12

Mouth and snout moderate in size; body cream to gray, overlain with numerous dark roundish spots; V 131-139; MVF 124-126135; to $62 \mathrm{~cm}$; NE Australia; Indo-Pacific Uropterygius marmoratus (Lacepède, 1803) $)^{5,9}$

10 Snout and jaws short, lower jaw shorter; teeth low and rounded or molariform, no caniniform teeth; teeth in upper jaw usually biserial; vomerine teeth molariform and continuous with median intermaxillary teeth

— Snout short to elongate, jaws usually about equal; some teeth sharp or caniniform; teeth in upper jaw uniserial or biserial; vomerine teeth molariform, rounded, or sharp, separated from median intermaxillary teeth

11 Anus posterior to midbody, tail about $30 \%$ of TL; body coloration dark brown to black, encircled by many narrow white to yellow rings; V 129-137; MVF 14-84-132; to $150 \mathrm{~cm}$; W, NW, NE Australia, widespread in Indo-Pacific from Africa to eastern Pacific Gymnomuraena zebra (Shaw, 1797) ${ }^{5,11}$

Anus about at mid-body, tail about $50 \%$ of TL Echidna.... 12

12 Body coloration uniform; V 117-127; MVF 6-52-122; to $36 \mathrm{~cm}$; W, NW Australia, Indo-Pacific Echidna unicolor Schultz, 19532,10

Body coloration blotched or barred

13 Body pale with 2 rows of stellate black blotches with pale (yellow or orange in life) centres; V 121-126; MVF 6-57-122; to $75 \mathrm{~cm}$; W, NW, N, NE, SE Australia, Indo-Pacific from Africa to eastern Pacific Echidna nebulosa (Ahl, 1789) 5

- Body with 20-30 contrasting dark and pale bars or rings encircling the body in young, becoming mottled brown and indistinct with age but bars visible near end of tail; V 119-126; MVF 6-52-122; to $72 \mathrm{~cm}$; NE Australia, Indo-Pacific . Echidna polyzona (Richardson, 1845) 
14 Body slender and very elongate, its depth $40 \times$ or more in TL

— Body stouter, its depth $30 \times$ or less in TL 16

15 Anterior nostrils simple tubes; chin lacks barbels; body cylindrical; body uniform brown, fins darker; V 185-208; MVF 9-78-197; to $394 \mathrm{~cm}$; N, NW, NE Australia, Indo-Pacific Strophidon sathete (Hamilton, 1822) (3,11 $^{3}$

Anterior nostrils with broad foliose enlargements; lower jaw tip with protruding barbels; body and tail laterally compressed; body yellow, black, or bright blue, fins yellow or white; V 276-281; MVF 5-90278; to $130 \mathrm{~cm}$; W, NE Australia, Indo-Pacific ..... Rhinomuraena quaesita Garman, $1888^{11}$

16 Jaws elongate and arched, meeting only at their tips; elongate canine teeth exposed when jaw is closed

_ Jaws not elongate and arched, closing completely or for most of their length; teeth not exposed when jaw is closed

17 Anterior nostrils with bilobate flaps on posterior margins; posterior nostrils in short, broad tubes; body uniform dark brown, fin margin paler; V 141-147; MVF 6-63-142; to 152 cm; NE Australia, IndoPacific to tropical eastern Pacific Enchelynassa canina (Quoy \& Gaimard, 1824) ${ }^{5}$

— Anterior nostrils without large flaps; body coloration various, either uniform dark brown or patterned Enchelycore.... 18

18 Body uniform brown with narrow pale (yellow in life) margin on fins; V 146-153; MVF 10-51-149; to $70 \mathrm{~cm}$; N, NW, NE Australia, Indo-Pacific Enchelycore bayeri (Schultz, 1953) ${ }^{11}$

Body pale, overlain with striking brown to dark mosaic pattern over entire body and fins; V 145-151; MVF 6-56-150; to $150 \mathrm{~cm}$; SE Australia, New Zealand; Easter Island Enchelycore ramosa (Griffin, 1926) ${ }^{8}$

19 Head small, jaws short; maxillary teeth in 2 short rows ending below posterior eye; no long caniniform teeth

_ Head large, jaws moderate to long; maxillary teeth in 1-2 rows extending to corner of mouth; caniniform teeth present

20 Dorsal-fin origin closer to anus than to gill opening; body light brown with diffuse brown mottling forming spots posteriorly; head pores in conspicuous white spots; fins pale; V 110-118; MVF 37-48-117; to $20 \mathrm{~cm}$; W, NW, NE Australia, Indo-Pacific Gymnothorax fuscomaculatus (Schultz, 1953) ${ }^{5}$

Dorsal-fin origin before gill opening

21 Gill opening in conspicuous dark spot; body tan to brown, sometimes with faint dark reticulations; V 132-149, MVF 4-53-139; to $30 \mathrm{~cm}$; W, NW, NE Australia, tropical Indo-Pacific . Gymnothorax melatremus Schultz, $1953^{5}$

Gill opening not in dark spot; colour not as above 22

22 Body and head uniformly pale; lines of small black dots marking head papillae; V 115-124; MVF 5-48-120; to $25 \mathrm{~cm}$; NE Australia, Indonesia and Philippines Gymnothorax castlei Böhlke \& Randall, $1999^{5}$

Body and fins with overlapping small brown spots; tip of snout and lower jaw pale, eye white in life; V125-137;MVF4-50-133; to 65 cm; NW, N, NE, SE Australia to $34^{\circ} \mathrm{S}$, Indo-Pacific ..... Gymnothorax thyrsoideus (Richardson, 1845) ${ }^{8,11}$ 
23 Body pale overlain with wide, dark bars, saddles, or spots forming bars

Body uniformly colored or marked other than described above

24 Body overlain with dark bars that meet along ventral surface; head barred but without spots; teeth smooth, long fangs present

- Body overlain with either bars or with dorsal saddles; head spotted; jaw teeth with fine serrations (may be difficult to discern), no fang-like teeth

25 Anterior nostril black; chin and throat bands reach just below lateral midline, not joined ventrally; a black spot at corner of jaw; V 125-135; MVF 5-52-131; to $75 \mathrm{~cm}$; NE Australia, tropical IndoPacific Gymnothorax rueppelliae (McClelland, 1844) ${ }^{5}$

- Anterior nostril pale; chin and throat bands continuous; jaw corner pale; V 126-134; MVF 4-51-130; to $58 \mathrm{~cm}$; NE Australia, tropical Indo-Pacific Gymnothorax enigmaticus McCosker \& Randall, $1982^{10}$

26 22-30 dorsal pairs of large saddle-like brown spots each associated with smaller ventral spot, forming diffuse broad bars; V 125-130; MVF 6-51-127; to $36 \mathrm{~cm}$; W and NE Australia .... Gymnothorax mccoskeri Smith \& Böhlke, $1997^{13}$

15-22 spotted dark bars well defined ventrally and continuous around anal fin, but obscured above lateral line; V 129-143; MVF 6-55-139; to $55 \mathrm{~cm}$; southern population from $\mathrm{W}$ and NE Australia (V 129-135), northern population from Japan to S China (V 135143) Gymnothorax minor (Temminck \& Schlegel, 1846) ${ }^{13}$

27 Body coloration uniform (brown, yellow, or green in life), lacking spots, bars, or complex pattern

Body patterned with pale or dark spots, blotches, or complex reticulations

28 Snout and jaws elongate; long fang-like teeth present

Snout and jaws relatively short; teeth moderate, sharp, but none fang-like

29 Coloration uniform tan to brown (may be paler ventrally), without contrasting marks; V 136-143; MVF 4-58-139; to $75 \mathrm{~cm}$; W, NW Australia, tropical Indo-Pacific Gymnothorax monochrous Bleeker, $1856^{7}$

Coloration uniform medium to dark brown (appearing green or yellow in life); pale streak on head dorsally, head pores dark; V 134-140; MVF 5-58-137; to $80 \mathrm{~cm}$; W, S, SE Australia, Tasmania, New Zealand, all south of $26^{\circ} \mathrm{S}$ Gymnothorax prasinus (Richardson, 1848) $)^{1,8}$

30 Coloration uniform medium brown; no contrasting marks on head or fins; jaw teeth smooth; V 110-118; MVF 6-47-114; a small species, to $30 \mathrm{~cm}$; NE Australia, western Pacific and Indian Ocean Gymnothorax pseudoherrei Böhlke, 2000 4

Coloration uniform brown, with contrasting marks on head and/or fins; jaw teeth serrate 
31 Body and fins uniform brown; posterior jaw pores in pale spots; V 127-133; MVF 5-53-131; a small species, to $30 \mathrm{~cm}$; Lord Howe Island; Hawaii and Red Sea Gymnothorax atolli (Pietschmann, 1935) ${ }^{1,5}$

Body coloration uniform brown; fins with contrasting colour 32

32 Body and fins uniform medium brown; narrow pale margin on fins; snout, dorsal head, and jaw pores dark; VF 6-68-151; to 88 $\mathrm{cm}$; SE Australia Gymnothorax austrinus n.sp. ${ }^{1}$

Body dark brown shading to darker brown to black on posterior fins and tail; V 110-124; MVF 6-44-121; to $39 \mathrm{~cm}$; NE Australia, Indo-Pacific Gymnothorax pindae Smith, $1962^{5}$

33 Body relatively stout, depth at anus equal to or greater than depth at gill opening, tail rounded; teeth numerous, no long fangs; intermaxillary teeth in 5 rows across, maxillary teeth biserial for all of their length

Body elongate, depth at anus less than depth at gill opening, tail tapering; teeth fewer, long fangs usually present; intermaxillary teeth usually in 3 rows across, maxillary teeth uniserial or biserial anteriorly

34 Head and body dark brown or black with numerous distinct small pale spots that extend onto snout; tip of tail pale (yellow in life), inside of mouth pale (white in life); V 127-132; MVF 5-52-130; to $100 \mathrm{~cm}$; NE Australia, Indo-Pacific to Galápagos Islands ..... Gymnothorax meleagris (Shaw, 1795)

Body dark with darker spots or with both pale and dark spots; inside of mouth not pale, tail tip patterned

35 Body dark with darker spots and mottling, some spots appearing in rows along body; anterior head region uniformly dark or indistinctly mottled; V 109-117; MVF 5-47-113; to $39 \mathrm{~cm}$; W, NW, NE Australia, tropical Indo-Pacific to tropical eastern Pacific Gymnothorax buroensis (Bleeker, 1857) ${ }^{5}$

Body colour highly variable, tan to brown with small pale spots (yellow in life) with dark spots superimposed, sometimes appearing as reticulated pattern on tail; head spotted; V 116-125; MVF 5-48-120; to $58 \mathrm{~cm}$; W, NW, NE and SE Australia, Indo-Pacific, an antitropical species found poleward of $15^{\circ} \mathrm{S}$ Gymnothorax eurostus (Abbott, 1861)

36 Body spotted, with discrete spots or with indistinct spots or blotches

Body with complex pattern of reticulations often forming vertical bars posteriorly

37 Pale spots or blotches on dark background or pale spots separated by dark reticulum

Dark spots on pale background or dark spots separated by pale reticulations

38 Pale spots distinct, about equal to or less than eye.

_ Pale spots diffuse, appearing as blotches, or separated by dark reticulum, larger than eye 
39 Distinct white spotting on head and anterior trunk, none or very few on tail; white margins on entire length of fins; V 142-146; MVF 6-64-145; to $20 \mathrm{~cm}$; NW and NE Australia Gymnothorax cephalospilus n.sp. ${ }^{1}$

Head, body, and tail spotted, but not predominantly on head and anterior trunk

40 Head, body, tail and fins medium to dark brown covered with small, close-set, pale spots of irregular shape, the spots similar on head, body, and fins; V 166-172; MVF 10-70-169; to $170 \mathrm{~cm}$; SE Australia and New Zealand.. Gymnothorax obesus (Whitley, 1932a) ${ }^{1}$

- Head, body and tail with pale spots of varying sizes, some widelyseparated or ocellated

41 Largest teeth serrate; small spots on head close-set, becoming fewer, larger and ocellate on tail; fins with pale margin; mouth bright yellow in life; V 131-139; MVF 3-52-134; to $100 \mathrm{~cm}$; NE Australia, tropical Indo-Pacific Gymnothorax nudivomer (Günther, 1867)

- Teeth smooth; small spots on head, becoming larger and segmented on body, sometimes ocellate on tail; fins with 1-2 rows spots; $\mathrm{V}$ 138-142; MVF 5-55-140; to $87 \mathrm{~cm}$; SE Australia, New Zealand, Taiwan and Japan Gymnothorax prionodon Ogilby, $1895^{1,8}$

42 Body dark brown to blackish, with large scattered indistinct grayish blotches; fins dark with black margin; head pores with fine brown rims; V 129-137; MVF 5-60-133; to $74 \mathrm{~cm}$; W, NW, NE Australia, Thailand? Gymnothorax longinquus (Whitley, 1948)

- Body tan to brown with large pale spots or blotches; fins with pale margins

43 Teeth serrate; head dusky or reticulated, body and tail with irregular pale spots separated by narrow dark reticulum; fins with pale or white margins; V 147-163; MVF 5-68-155; to $103 \mathrm{~cm}$; NE Australia, central and western Pacific and Indian oceans, a deepwater species Gymnothorax intesi (Fourmanoir \& Rivaton, 1979)

Teeth smooth 44

44 Overall coloration brown with large, pale, snowflake-like blotches on head, body and fins (sometimes fewer and smaller on tail), colour of uniform intensity; anal fin with conspicuous pale margin; V 136-149; MVF 5-55-141; to 92 cm; NE Australia, Hawaii, Japan, Taiwan, Society Islands Gymnothorax kidako (Temminck \& Schlegel, 1846)

- Body tan with about 3 rows of large pale spots dorsally; head, abdomen, and ventral tail region pale and unspotted; anal fin dark basally with narrow pale margin; V 134-141; MVF 4-57-137; to $58 \mathrm{~cm}$; $\mathrm{W}$ and $\mathrm{S}$ Australia Gymnothorax woodwardi McCulloch, $1912^{1}$

45 Dark spots as large as or larger than eye 46

_ Dark spots small and round, sometimes overlapping or sometimes aggregating to form complex pattern 
46 Gill opening in a prominent dark blotch; juveniles tan with distinct dark spots on head, body, and fins, the spots becoming large and diffusely speckled with pale spots in adults; fins pale in juveniles, patterned in adults; V 137-143; MVF 6-60-141; to $250 \mathrm{~cm}$; NW, N, NE Australia, tropical Indo-Pacific to tropical eastern Pacific Gymnothorax javanicus (Bleeker, 1859) ${ }^{5}$

Gill opening not in a prominent dark blotch

47 Dorsal-fin origin behind gill opening (but fins obscured by flabby flesh, often mistaken as a species of Uropterygius); coloration tan with large irregular dark spots on head, body, and fins; a series of elongate spots forming 5-7 horizontal lines in branchial area; snout and lower jaw pale; V 141-148; MVF 12-70-144; to $70 \mathrm{~cm}$; NE Australia, western Pacific, inhabits estuaries or rivers Gymnothorax polyuranodon (Bleeker, 1853)

_ Dorsal-fin origin before gill opening; dark spots polygonal on body, interspaces appearing as a reticulum

48 Color pattern uniform on head, body and fins; large, black, polygonal spots separated by a narrow, pale reticulum (in small specimens the spots are rounder and the reticulum is wider); $\mathrm{V}$ 138-144; MVF 5-60-141; to $110 \mathrm{~cm}$; NW, N, NE, SE Australia, tropical Indo-Pacific .................................... Gymnothorax favagineus Bloch \& Schneider, $1801^{12}$

— Head uniform brown or mottled; body and fins with irregular brown rectangular spots separated by a narrow pale reticulum; $\mathrm{V}$ 126-138; MVF 5-53-132; to $150 \mathrm{~cm}$; NW, N, NE Australia, tropical Indo-Pacific to eastern Pacific Gymnothorax undulatus (Lacepède, 1803)

49 Dark spots small and round, may be overlapping but not aggregating to form a complex pattern...

Dark spots aggregating to form a complex pattern of larger spots 52

50 Dark spots few, eye-sized and well-separated; body tan with 2-4 rows of spots along trunk and tail, abdomen unspotted; a conspicuous series of about 5 spots in 2 oblique rows behind eye; V 128-142; MVF 5-54-133; to $68 \mathrm{~cm}$; W, NW, NE Australia, IndoPacific Gymnothorax fimbriatus (Bennett, 1832) ${ }^{11}$

Dark spots numerous, small and close-set or overlapping

51 Gill opening in a dark blotch; head, body and fins with overlapping dark spots; posterior fins with narrow pale margins (yellow or green in life); V 132-140; MVF 5-58-136; to $120 \mathrm{~cm}$; NW, N, NE Australia, Indo Pacific, occasionally to eastern Pacific Gymnothorax flavimarginatus (Rüppell, 1830)

_ Gill opening not dark; body dark with darker mottling and spots on head, body, and fins; snout, nostrils and head pores dark; V 137-144; MVF6-58-141; to $130 \mathrm{~cm}$; Kermadec, Lord Howe, and Norfolk islands, New Zealand; Easter Island, Chile and Peru Gymnothorax porphyreus (Guichenot, 1848) ${ }^{1}$

52 Dorsal-fin origin above or near gill opening; vomerine teeth biserial, diverging anteriorly in adults; colour highly variable: juveniles pale with irregular dark spots, unspotted ventrally; spots usually spreading onto abdomen with growth; adults pale with small dark dots that aggregate to form large dark rosettes in 2-3 rows along body; some large adults very dark overall, with rows 
of darker rosettes; V 128-135; MVF 9-58-131; to $140 \mathrm{~cm}$; NW,

N, NE Australia, tropical Indo-Pacific to eastern Pacific Gymnothorax pictus (Ahl, 1789)

Dorsal-fin origin well before gill opening

53 Body pale with small dark spots aggregating to form larger spots forming about 4 irregular rows along body; pattern present on top of head; fins patterned, with narrow pale margin posteriorly; V 122-135; MVF 4-56-130; to $80 \mathrm{~cm}$; NW Australia, western Pacific Gymnothorax pseudothyrsoideus (Bleeker, 1852b) ${ }^{11}$

Body gray or brown with dark spots on head, body, and fins, with aggregations of larger dark spots forming scattered larger blotches; fins patterned basally, anal fin with conspicuous pale margin; V 141-144; MVF 5-58-142; to 55 cm; Middleton and Elizabeth Reefs and Lord Howe Island Gymnothorax annasona Whitley, $1937^{1}$

54 Dark spots on head 55

Both dark and pale marks on head 57

55 Lines of faint, small dark dots marking head papillae and anterior lateral-line papillae; body with brown and pale reticulations forming cloud-like spots; V 130-134; MVF 4-52-132; to $68 \mathrm{~cm}$; Norfolk and Kermadec islands, New Zealand Gymnothorax nubilus (Richardson, 1848) ${ }^{1}$

Conspicuous dark spots behind eye. 56

56 Single row of 3-5 dark oval blotches in a line behind eye extending onto anterior trunk region; body with brown and pale vertical reticulations; V 123-133; MVF 6-50-129; to $47 \mathrm{~cm}$; NW, NE Australia, Indo-Pacific .... Gymnothorax margaritophorus (Bleeker, 1865) ${ }^{11}$

2-3 rows of prominent dark brown spots (equal to or smaller than eye) behind eye; body with pale and brown lattice-like reticulations, sometimes appearing as pale spots on tail; V116125; MVF 4-50-120; to $46 \mathrm{~cm}$; NW, NE, SE Australia, to $34^{\circ} \mathrm{S}$ Gymnothorax cribroris Whitley, 1932 $\mathrm{a}^{1,8}$

57 Jaw pores not in white spots; head brown, marked dorsally from snout to occiput with a pale dorsal streak with brown borders; body tan, overlain with dark brown, irregular oblique bars extending from dorsum to midflank anteriorly, extending ventrally and onto dorsal fin on tail; V 127-135; MVF 5-51-131; to $32 \mathrm{~cm}$; NE Australia, Indo-Pacific Gymnothorax gracilicaudus Jenkins, $1903^{5}$

Jaw pores in white spots

58 Posterior 2-3 pores of upper and lower jaws in pale spots, extending as a distinct pale blotch from upper to lower jaw; a distinct brown spot at corner of mouth; body and tail with complex, lichen-like blotches; V 120-129; MVF 5-49-125; to $50 \mathrm{~cm}$; NW, NE Australia, tropical Indo-Pacific Gymnothorax chilospilus Bleeker, $1865^{5}$

- Posterior 2-3 pores of upper and lower jaws enclosed by white bars that are continuous across lower jaw; a distinct irregular brown mark with pale borders behind eye; body with pattern of oblique broken vertical bars that become dark with bright white borders on posterior fins; V 123-130; MVF 6-48-126; to $47 \mathrm{~cm}$; W, NW, NE Australia, tropical Indo-Pacific Gymnothorax zonipectis Seale, $1906^{11}$ 


\section{Rare and poorly known species of Australian Gymnothorax}

\section{Gymnothorax annasona Whitley, 1937}

Lord Howe Island moray

Fig. 2

Gymnothorax flavimarginatus annasona Whitley, 1937: 220. Holotype AMS IA.6867, 19 inches (current measurement 508 mm) TL; Middleton Reef, $\mathrm{N}$ of Lord Howe Island, near the "Annasona" wreck, spear; Mr Tom Patton; 18 April 1936.

Description. A moderately large, elongate moray, depth at gill opening 13-21, depth at anus 15-25 in TL; anus before midbody, preanal length 2.1-2.4. Head moderately elongate, 7.2-8.4 in TL; snout moderately long and tapering, 4.7-5.5 in HL; jaws long, upper jaw 2.2-2.7 in HL. Eye moderate, 8.0-13 in HL, above midgape. Anterior nostril in long narrow tube; posterior nostril a pore above and behind anterior margin of eye. Head pores typical; two branchial pores above and just before gill opening; dorsal-fin origin above or before first pore, closer to gill opening than to rictus. Gill opening at midside. Predorsal vertebrae 4-6, preanal vertebrae 56-59, total vertebrae 141-144; MVF 5-58-142 (9).

Teeth large, triangular and smooth, uniserial in adults. Outer intermaxillary teeth 6 plus $1-4$ (usually 3 ) tiny teeth between posterior teeth; 3 long median fangs. Maxillary teeth of small specimens (to $350 \mathrm{~mm}$ ) an inner row of 1-4 long teeth and outer row of 11-18 teeth, tapering in size posteriorly; large specimens with an outer row of 11-13 teeth only. Vomerine teeth small and hidden, 6-11 in single row. Dentary teeth of small specimens 3-5 large inner teeth enclosed by $4-8$ small outer teeth, continuing as row of 11-18 teeth; large specimens with single row of 15-18 teeth, large anteriorly, tapering in size posteriorly.

Coloration mottled and spotted on head, body and fins. Head with small spots, body and tail covered with small overlapping rounded dark spots, overlain with scattered larger dark blotches formed by aggregations of darker spots. Dorsal fin high, with basal coloration like body, the margin pale for posterior third to two-thirds of fin; anal fin spotted basally, with conspicuous pale margin for entire extent.

Notes on holotype. The holotype of Gymnothorax annasona is hard and dry, and has a missing and regenerated tail (as noted by Whitley); its total length $(508+\mathrm{mm})$ is longer than Whitley's stated 19 inches (483 mm). Coloration as described above. Proportions and meristics are imprecise due to the missing tail; VF 4-58-133+. Teeth large, triangular and smooth, few in number; intermaxillary teeth in three rows with two median fangs; maxillary, vomerine, and dentary teeth uniserial.

Remarks. The largest specimen we examined is $750 \mathrm{~mm}$; it is said to reach $1500 \mathrm{~mm}$ (Coleman, 1983: 40). None of the study specimens is mature; a $553 \mathrm{~mm}$ specimen is an immature female. It has been taken at Middleton and Elizabeth Reefs, and Lord Howe Island, all off New South Wales, in the Tasman Sea, $29-32^{\circ} \mathrm{S}$. It is common at Lord Howe Island where it was seen in shallow waters of coral reefs at depths to $15 \mathrm{~m}$, observed lurking in crevices during the day and actively swimming at night (John E. Randall, pers. comm.). Its life colors in an underwater colour photo

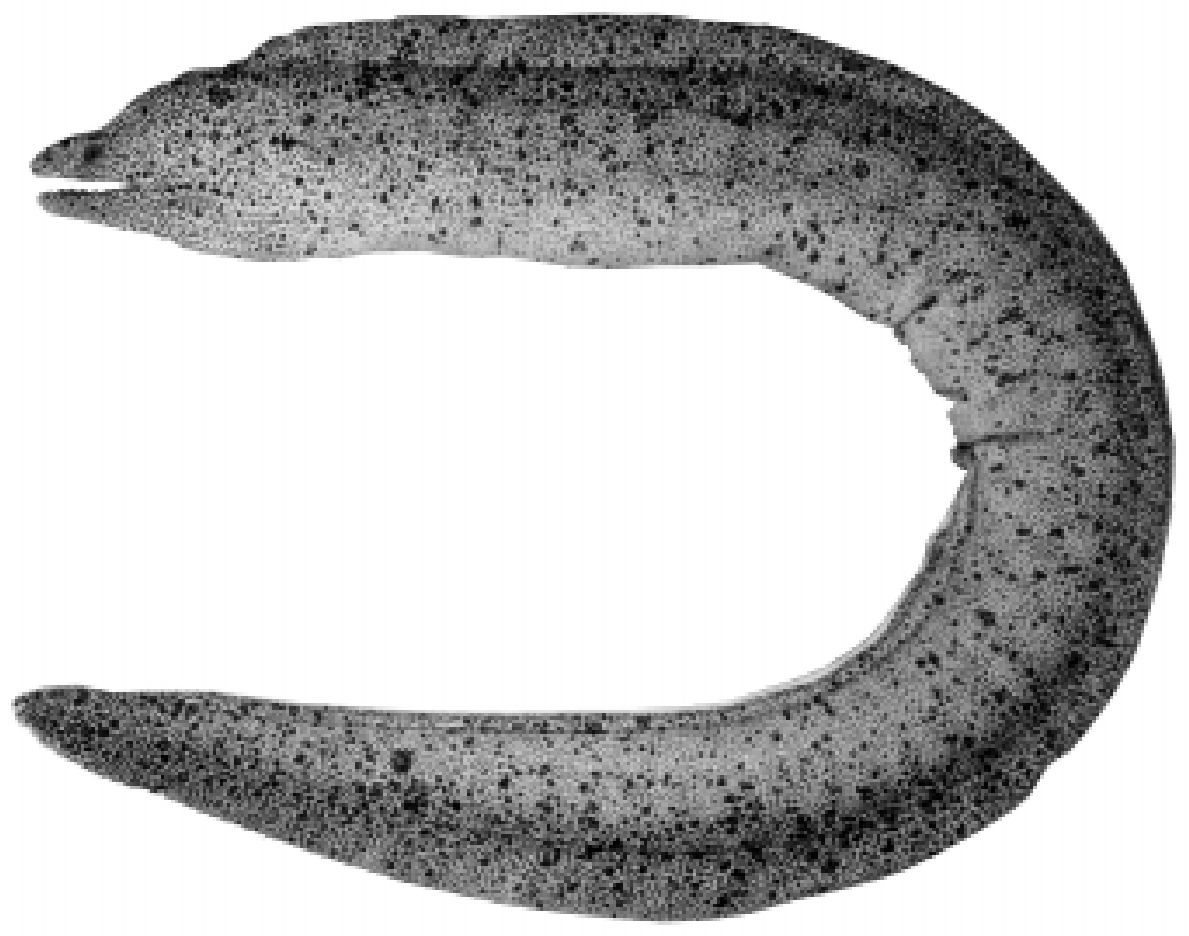

Figure 2. Gymnothorax annasona; $705 \mathrm{~mm}$ TL, Lord Howe Island, photo by J.E. Randall. 
(Coleman, 1983: 40) are dark brown spots on a yellowishtan background.

Gymnothorax annasona was described as a subspecies of G. flavimarginatus, a common tropical species with somewhat similar coloration but that lacks the large aggregates of spots, has a prominent black blotch surrounding the gill opening, and also has fewer vertebrae (MVF 5-58-136). We elevate Whitley's subspecies to species rank, based on the differences in coloration and vertebral counts seen in the holotype and additional specimens. It is also similar to Gymnothorax parini from Walters Shoals in the western Indian Ocean, which has a lichenous colour pattern, a more prominent bright margin on the fins, and more vertebrae (MVF 4-56-147).

Study material. Fourteen specimens, 163-750 mm TL. MIDDLETON REEF: AMS IA.6867, $508 \mathrm{~mm}$, holotype of Gymnothorax flavimarginatus annasona; CAS 87882, 2: 163-232 mm. ELIZABETH REEF: AMS I.27157-100, 238 mm. LORD HOWE ISLAND: AMS I.10662, $551 \mathrm{~mm}$; AMS I.12099, 750 mm; AMS I.17369-006, 3: 320-481 mm. I.20257-018, $538 \mathrm{~mm}$; BPBM 14777, $553 \mathrm{~mm}$; BPBM 14838, 340 mm; BPBM 14867, 2: 218-238 mm.

\section{Gymnothorax atolli (Pietschmann, 1935)}

\section{Atoll moray}

Fig. 3

Heteromyrus atolli Pietschmann, 1935: 93 (holotype NMW 65106; type locality South East Island, Pearl and Hermes Reef, Hawaiian Islands).

Gymnothorax sp. A. Allen et al., 1976: 377 (Lord Howe Island). Gymnothorax australicola. (Not of Lavenberg, 1992). Lavenberg, 1992: 59 (1 paratype, BPBM 14945 from Lord Howe Island).

Description. A small, moderately elongate moray, depth at gill opening 17-22 and depth at anus $22-27$ in TL; anus before midbody, preanal length $2.0-2.2$ in TL. Head moderate, its length 7.4-9.1 in TL; snout short and rounded, overhanging lower jaw, 5.2-7.0 in HL; upper jaw short, 2.6-3.3 in HL; lips papillose. Eye small, 10-14 in HL, notably closer to rictus than to snout tip. Anterior nostril in moderate tube; posterior nostril above and behind anterior margin of eye, with raised crenulate rim. Only one branchial pore, above and before gill opening; remaining head pores typical; dorsal-fin origin about midway between rictus and gill opening, above and before branchial pore. Gill opening inconspicuous, a diagonal slit at midbody. Predorsal vertebrae 4-6, preanal vertebrae 51-55; total vertebrae 127133; MVF 5-53-131 (8).

Teeth stout and triangular, largest intermaxillary and dentary teeth serrate; maxillary teeth biserial. Peripheral intermaxillary teeth 5-6, the posterior three large and serrate; 0-2 median teeth, the second long, thin and depressible. Inner row of 8-14 tall, slender, well-spaced maxillary teeth; outer row of 15-24 short rounded teeth. On vomer 4-12 short conical teeth in irregular row. On dentary main row of 12-18 consisting of 3-5 large triangular serrate anterior teeth followed by $9-14$ progressively smaller teeth; 1-4 small outer teeth flanking the large anterior teeth.
Coloration of head, body and fins medium brown; the small Hawaiian specimens uniformly colored with few pale areas, the two largest specimens (244-293 mm) mottled all over with pale blotches. Fins of some specimens pale, those of patterned specimens with body pattern. Ventral surface of head and abdomen sometimes pale. Eye ringed with dark brown pigment; head pores large and conspicuous, the anterior pores with brown pigmented rims and the posterior 1-2 upper jaw pores and the last 2-3 mandibular pores in white areas (these not obvious in patterned specimens); branchial pore small, with a fine brown-pigmented rim. Small specimens coated with mucus.

Notes on holotype. Described as Heteromyrus atolli, this species was largely ignored since its description until recent re-examination of the holotype indicated that it is a valid species with characters and coloration as described above (see Böhlke \& Randall, 2000: 228).

Remarks. Gymnothorax atolli is a small species, the largest known specimen $293 \mathrm{~mm}$ TL; two females (206-244 mm) had $0.8-0.9 \mathrm{~mm}$ eggs. It is found in the Hawaiian Islands, from Pearl and Hermes Reef in the north and from Midway Atoll, the Midway specimens collected at depths to $8 \mathrm{~m}$. Three additional specimens from disjunct localities of Japan, Lord Howe Island, and the Red Sea (two of them larger and with mottled coloration), were thought to perhaps represent a new species (the Red Sea specimen is desiccated, in poor condition and missing the end of its tail). They were re-examined during the course of this study and are now considered to represent larger specimens of $G$. atolli with slightly different coloration. The paratype of G. australicola from Lord Howe Island (BPBM 14945), which was conspicuous in having a vertebral count much lower than that of any of the other types, is this species.

Gymnothorax atolli is characterised by its overall brown or mottled coloration, single branchial pore, some serrate teeth and biserial maxillary dentition. It most similar to $G$. australicola, which also is a small brown moray with one

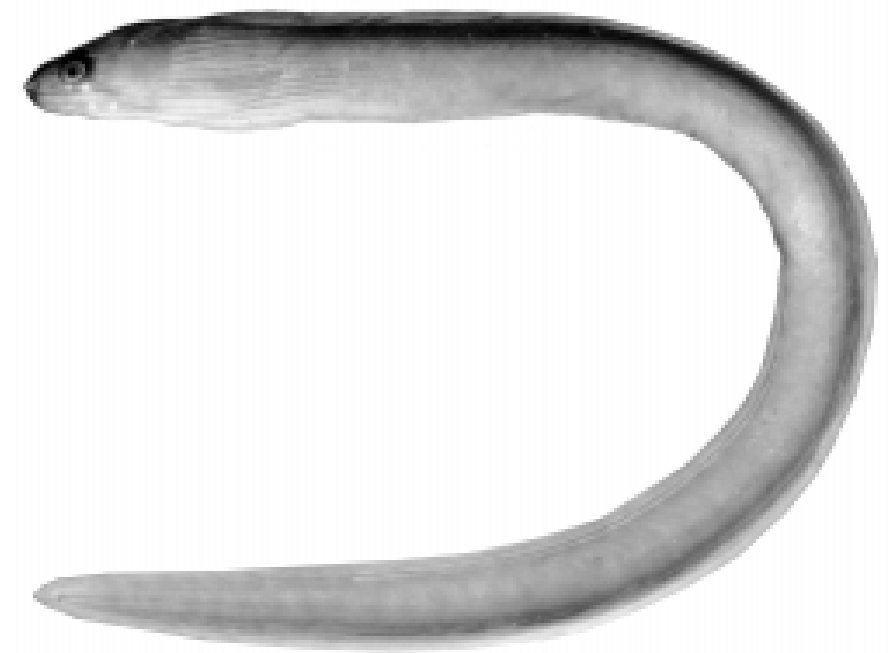

Figure 3. Gymnothorax atolli; BPBM 34833, $160 \mathrm{~mm}$ TL, Midway Atoll, photo by J.E. Randall. 
branchial pore, some teeth serrate, and biserial maxillary teeth; G. australicola differs in having a shorter preanal length (2.2-2.5 for australicola, vs. 2.0-2.2 for atolli) and more vertebrae (MVF 5-53-144 vs. 5-53-131 respectively).

Study material. Ten specimens, 75-244 mm TL. HAWAIIAN ISLANDS: Pearl and Hermes Reef: NMW 65106, $192 \mathrm{~mm}$, holotype of Heteromyrus atolli. Midway Atoll: ANSP 176590, $206 \mathrm{~mm}$; BPBM 34833, 3: 75-160 mm; BPBM 34878, 161 mm. JAPAN: Miyaki-Jima: BPBM 18979, 244 mm. LORD HOWE ISLAND: BPBM 14927, 293 mm; BPBM 14945, $128 \mathrm{~mm}$, paratype of Gymnothorax australicola. RED SEA: Eilat: HUJ 15133, 203+ mm.

\section{Gymnothorax austrinus n.sp.}

Southern moray

Figs. 4, 5, Pl. 1

Type material HoLOTYPE: NMV A.17858, $882 \mathrm{~mm}$ TL, female; Australia, Victoria, Port Philip Bay, Half Moon Bay, 3758'S 14501'E; F. McCoy; 1 June 1884.

Diagnosis. A large, brown moray with tapering tail; anus behind midbody, preanal length 1.8 in TL; head moderate, 8.5 in TL; depth at gill opening 18 in TL; teeth uniserial, few and highly serrated, no median intermaxillary or vomerine teeth; VF 6-68-151.

Measurements (in mm) and counts of the holotype. Total length 882 ; preanal length 478 ; head length 104 ; snout to dorsal-fin origin 85.6; depth at gill opening 48.5; depth at anus 41.6; snout length 19.0; length upper jaw 34.5 ; length lower jaw 37.0; eye diameter 6.9; interorbital width 14.0. Head pores: branchial 2; supraorbital $1+2$; infraorbital 5; mandibular 6-7. Predorsal vertebrae 6, preanal vertebrae 68 , total vertebrae 151 .

Description. A large, elongate, moray with tapering tail, depth at gill opening 18, depth at anus 21 in TL; anus behind midbody, preanal length 1.9 in TL. Head moderate, its length 8.5 in TL; snout short, 5.5 in HL; jaws slightly curved and short, upper jaw 3.0 in HL. Eye above midgape, small, 15 in HL. Anterior nostril in short, small tube; posterior nostril above and before eye, small, with slightly raised rim. Head pores with some variation from the usual muraenine condition; the 2 branchial pores very small and above and before gill opening; 5 infraorbital pores, the first just behind anterior nostril and the fifth below posterior margin of eye, the "extra" pore between and above the first and second; 7 mandibular pores on the left side, 6 on right side. Dorsalfin origin before gill opening, between first and second branchial pores; gill opening a small slit at midside. Predorsal vertebrae 6, preanal vertebrae 68, total vertebrae 151 .

Teeth strong and triangular, highly serrate, upper jaw teeth very few. Five stout intermaxillary teeth continuous with 5-7 maxillary teeth, the anterior teeth large and serrate on both margins and with posterior basal knob, becoming smaller posteriorly. No median intermaxillary teeth and none on vomer. Sixteen teeth on each side of lower jaw, large and serrate anteriorly, tapering in size posteriorly.

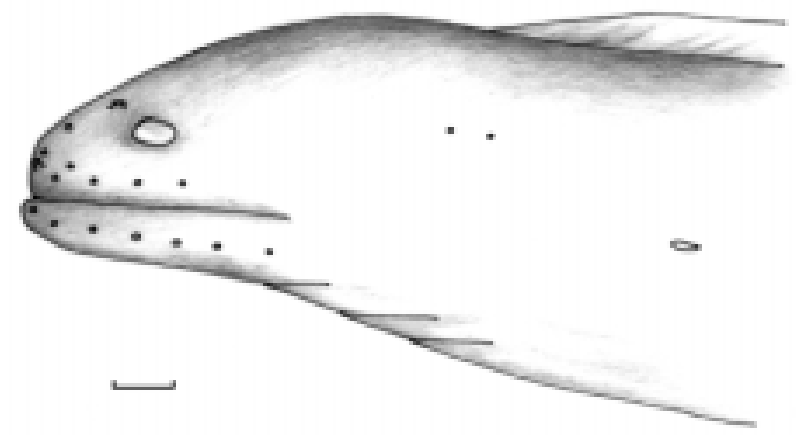

Figure 4. Gymnothorax austrinus; NMV A.17858, $882 \mathrm{~mm}$ TL, holotype, Port Philip Bay, Victoria, Australia; diagram of head; line $=10 \mathrm{~mm}$

Overall colour medium brown, with fine dark striations in folds of skin; abdomen pale. Snout and lower jaw dark, top of head dark with darker mottling between eyes; anterior 3-4 jaw pores pale, branchial pores with faint brown rims. Very narrow pale margin on all fins, that of dorsal fin faint anteriorly.

Remarks. The single $882 \mathrm{~mm}$ specimen was collected many years ago off the southern coast of Victoria, Australia; it is a ripe female with $\approx 1 \mathrm{~mm}$ eggs. It first appeared to be similar to a large specimen of Gymnothorax prasinus, also taken off Victoria, but it has a much more elongate and tapering body, the anterior head region is noticeably dark, and a narrow pale margin is visible on the fins. In addition, it has much different dentition, the teeth few and highly serrate, and the vertebral count is unusual and can be matched with no known species.

Etymology. From the Latin austrinus "southern". To be treated as an adjective.

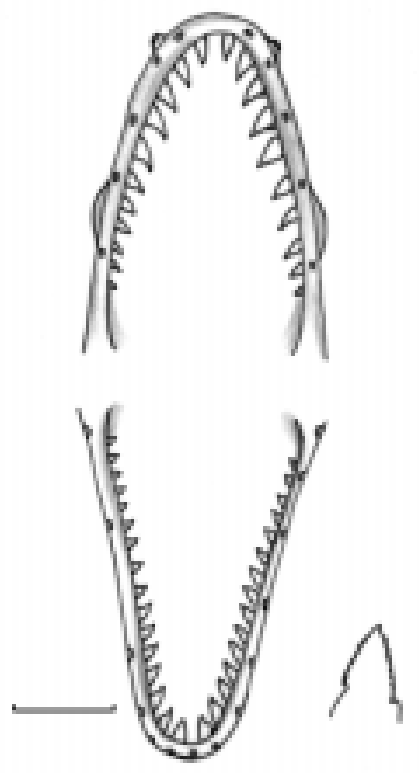

Figure 5. Gymnothorax austrinus; NMV A.17858, 882 mm TL, holotype; diagram of dentition; inset diagram of serrate tooth; line $=10 \mathrm{~mm}$. 


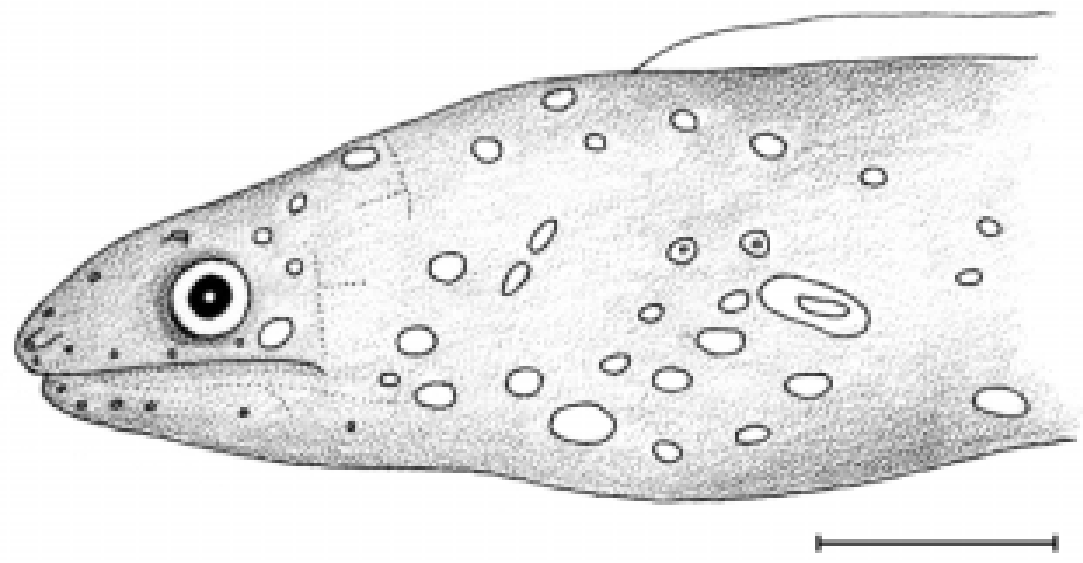

Figure 6. Gymnothorax cephalospilus; CAS 212449, $154 \mathrm{~mm}$ TL, paratype, off Port Macquarie, NSW, Australia; diagram of head; line $=10 \mathrm{~mm}$.

\section{Gymnothorax cephalospilus n.sp.}

Head-spot moray

Figs. 6, 7; Pl. 1

Gymnothorax sp. 4. Sainsbury et al., 1984: 331.

Type material HOLOTYPE: AMS I.37982.001, $171 \mathrm{~mm}$ TL; Australia, NSW, off Port Macquarie, $31^{\circ} 16^{\prime} \mathrm{S} 153^{\circ} 10^{\prime} \mathrm{E}$, lobster trap at $134 \mathrm{~m}$; K. Graham on the FV San Simeon; 18 June 1999. PARATYPES (3): ANSP 177865, $159 \mathrm{~mm}$, and CAS 212449, $154 \mathrm{~mm}$; same data as holotype. CSIRO CA2928, 202 mm; Western Australia, N of Dampier Archipelago, $19^{\circ} 25^{\prime} \mathrm{S} 116^{\circ} 38^{\prime} \mathrm{E}, 125 \mathrm{~m}$; 17 Aug. 1982.

Diagnosis. A small, slender, dark brown moray with contrasting eye-sized white spots on head; spots fewer toward anus, very few or lacking on tail; anus at midbody, preanal length 2.0 in TL; depth at gill opening 18-22 in TL; head 8.2-9.3 in TL; teeth stout, no long canines; MVF 6-64-145.

Measurements (in mm) and counts of the holotype: total length 171; preanal length 85; head length 20.7; snout to dorsal-fin origin 18.2; depth at gill opening 9.3; depth at anus 6.5; length upper jaw 7.1; length lower jaw 6.9; snout length 3.4; eye diameter 2.2; interorbital width 2.5 . Head pores: branchial 2; supraorbital $1+2$; infraorbital 4 ; mandibular 6 . Teeth: outer intermaxillary $7-7$, median intermaxillary 2; inner maxillary 3-4, outer maxillary 9; vomerine 6; dentary 14-16 + 3-5 outer teeth. Predorsal vertebrae 5, preanal vertebrae 64, total vertebrae 146 .

Description. A small, slender moray, depth at gill opening 18-22 and depth at anus 26-29 in TL; anus at midbody, preanal length 2.0 in TL. Head moderate, 8.2-9.3 in TL; snout moderate, 5.2-6.1 in HL; jaws moderate, upper jaw 2.6-3.2 in HL; eye above gape, closer to rictus than to snout tip, its diameter 9.3-11 in HL. Lips papillose. Anterior nostril in moderate tube just reaching edge of jaw; posterior nostril above and before eye, with slightly raised, crenulate margin. Head pores typical (the second supraorbital pore
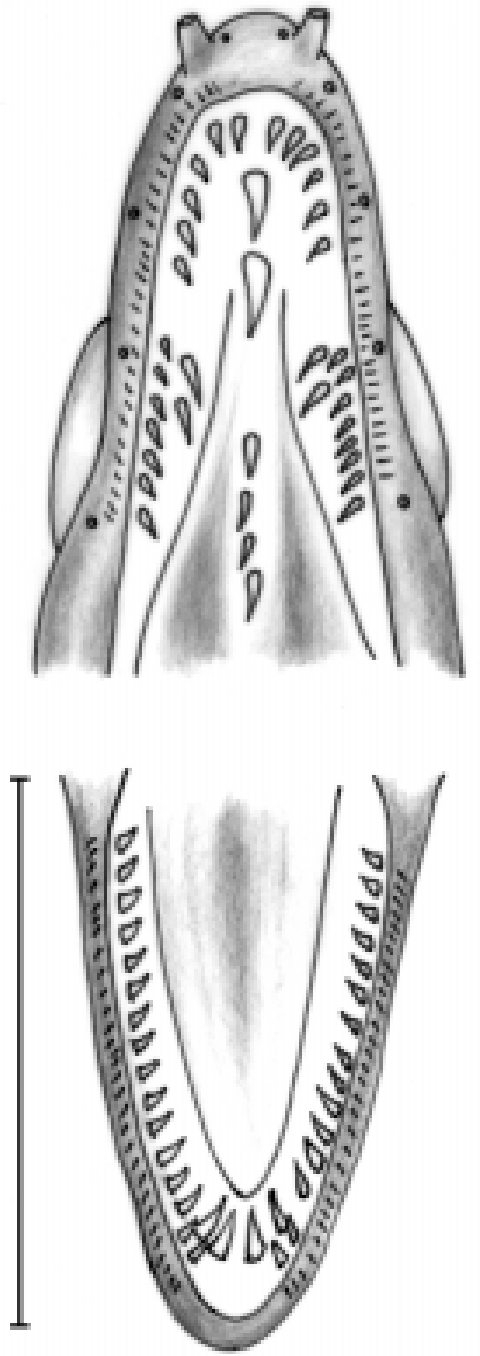

Figure 7. Gymnothorafx cephalospilus; CAS 212449, $154 \mathrm{~mm}$ TL, paratype; diagram of dentition; line $=10 \mathrm{~mm}$.

double on one side of one specimen), 2 branchial pores above and before gill opening. Dorsal-fin origin above second pore, closer to gill opening than to rictus. Gill opening a small slit at midside. Predorsal vertebrae 5-7, preanal vertebrae 6365, total vertebrae 142-146; MVF 6-64-145 (4).

Teeth stout, no long canines. Peripheral intermaxillary teeth $6-8$, the posterior 3 increasingly larger (the last teeth in the largest specimen with a "rough" edge posteriorly, suggesting that larger specimens may develop serrate teeth); 2 short stout median teeth. Short anterior inner row of 2-3 long slender maxillary teeth, outer row of 8-12 short triangular teeth. Single row of 5-8 short vomerine teeth. Dentary teeth in one row of $13-16$ teeth, the anterior 2-5 largest and flanked with 1-5 smaller outer teeth.

Dark brown with contrasting bright white margins on fins and white spots that are numerous on head, fewer and in about 2 rows dorsally between head and anus, and lacking or only very few dorsal spots on tail. Fine lines of pale papillae outline posterior nostril and head canals; all head pores with white rims; gill opening and anus sometimes pale. 
Dorsal fin dark basally, anal fin dark or with body colour basally, both fins with bright white margins for entire extent. The single specimen collected in 1982 has faded to medium brown with pale spots on head and anterior body, fin margins pale, and lines of head papillae are only faintly visible.

Remarks. All known specimens are small, the largest is $202 \mathrm{~mm}$ TL. The gonads of all are immature, indicating it probably grows to larger size. It is known from two collections off eastern and western Australia, both from deep waters of 125-134 m (one collection from a lobster trap). Its scarcity in collections is probably due to limited collecting in its deep-water habitat and to its small size.

These specimens differ from all known morays in their dark brown coloration with contrasting spotted head and bright fin margins, and in vertebral formula.

Etymology. From the Greek kephale, "head", and spilos, "spot". To be treated as a noun in apposition.

\section{Gymnothorax cribroris Whitley, 1932a}

\section{Sieved moray}

Fig. 8

Gymnothorax cribroris Whitley, 1932a: 330, pl. 39 (fig. 2). Holotype AMS IA.5012, 260 (252) mm TL; Northwest Islet, Capricorn Group, Queensland, Australia; G.P. Whitley; May 1931.

Description. A moderately large, elongate moray with tapering tail; depth at gill opening 15-20, depth at anus 15-21 in TL; anus before midbody, preanal length $2.1-2.3$ in TL. Head moderately elongate, 7.3-8.6 in TL; snout 4.96.2 and upper jaw 2.4-2.9 in HL. Eye moderately large, 8.4-10 in HL, above midgape. Anterior nostril in long tube; posterior nostril with rim, above and behind anterior margin of eye. Head pores typical; two branchial pores above and before gill opening; dorsal-fin origin above first pore. Gill opening at midside. Predorsal vertebrae 3-6, preanal vertebrae 48-51, total vertebrae 116-125; MVF 4-50-120 (11).

Teeth strong and smooth, uniserial in adults. Peripheral intermaxillary teeth 5-6, with 1-4 tiny teeth between posterior teeth; usually 3 long median fangs. Maxilla with inner row of 1-3 long slender teeth in specimens less than $300 \mathrm{~mm}$, plus outer row of 9-14 smaller teeth, becoming smaller posteriorly; single row of 9-11 teeth in large specimens. Vomerine teeth 6-14 in single row. On dentary of small specimens 2-4 large inner teeth enclosed by 3-6 small outer teeth continuing as row of 12-23 progressively smaller teeth; a single row of 13-16 teeth in large specimens.

Overall pattern of pale spots and blotches separated by brown reticulations; small pale spots on head, becoming lichenous or snowflake-like on body and tail; occiput conspicuously marked with several rows of larger dark brown spots. Lower jaw and thorax uniformly pale or with faint pattern; mouth angle and gill opening dusky; anterior nostril dark, posterior nostril with dark rim. Dorsal fin patterned, becoming dark posteriorly, with pale margin near tip of tail; anal fin patterned basally, with pale margin for entire extent. Color photographs (Sainsbury et al., 1984: 55; Randall et al., 1997: 36; Kuiter, 1997: 31) show dark brown spots and reticulations, the background and snowflake pattern yellowish-tan.

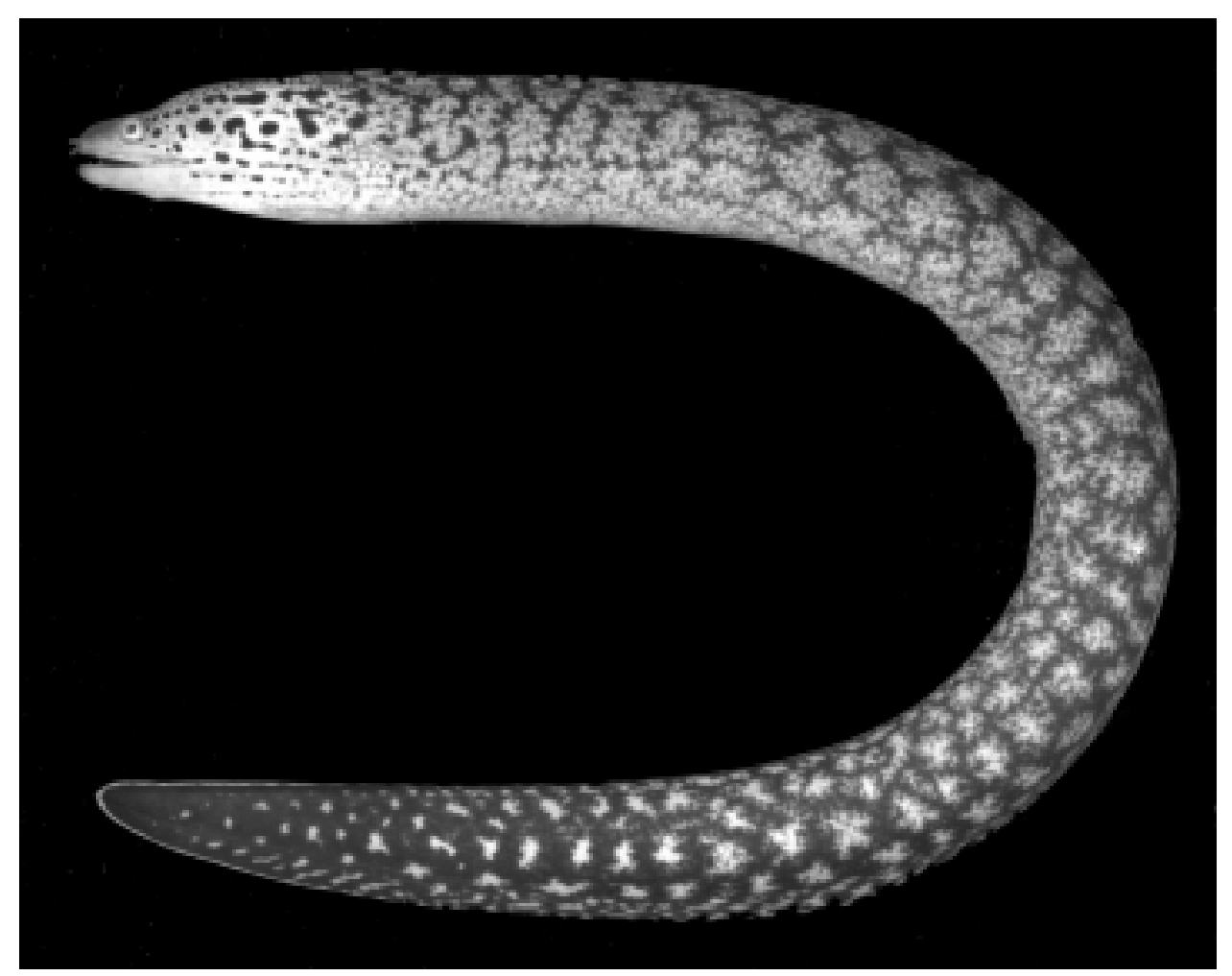

Figure 8. Gymnothorax cribroris; BPBM, 343 mm TL; One Tree Island; photo by J.E. Randall 

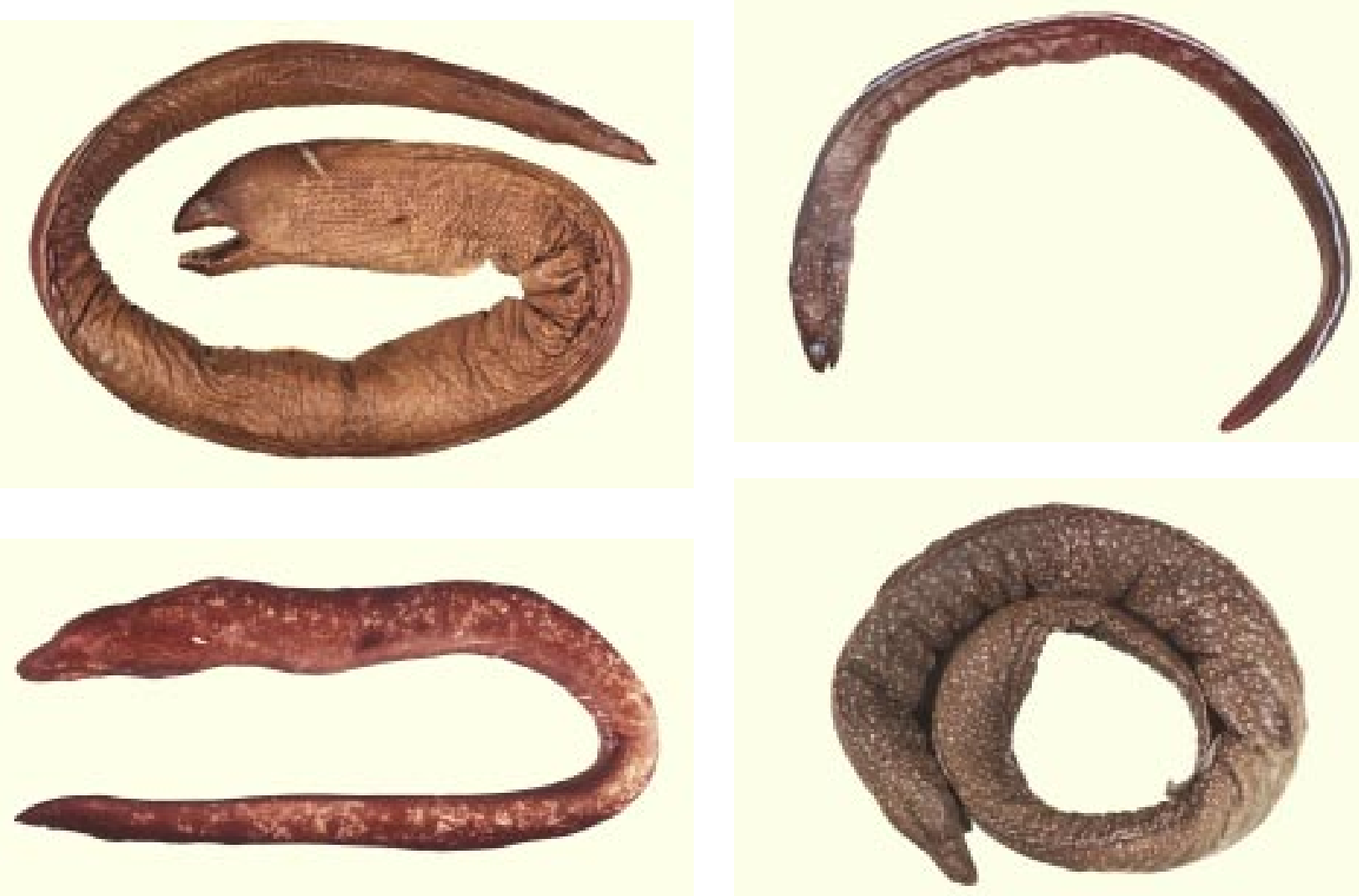

Plate 1. Upper left: Gymnothorax austrinus, NMV A.17858, $882 \mathrm{~mm}$ TL, holotype; Victoria, Australia. Upper right: Gymnothorax cephalospilus, AMS I.37982.001, $171 \mathrm{~mm}$ TL, holotype; New South Wales, Australia. Lower left: Gymnothorax longinquus; AMS I.21943.017, 490 mm; Arafura Sea; photo courtesy of A. Graham. Lower right: Gymnothorax obesus; AMS IA.2658, 730 mm; paratype of Uropterygius obesus; off Montague Island, NSW, Australia.

Notes on holotype. The holotype of Gymnothorax cribroris is in fair condition, moderately small,exhibiting coloration as described above. Head pores typical except 3 branchial pores on left side. Preanal length 2.1 in TL; VF 4-51-116. Teeth strong and smooth, typical juvenile dentition; 3 rows intermaxillary teeth,median row of 3 fangs; maxillary and dentary teeth biserial anteriorly; vomerine teeth uniserial.

Remarks. The largest specimen we examined is $460 \mathrm{~mm}$; none of the specimens was mature. It is taken off the east coast of Australia, from the Great Barrier Reef to Sydney Harbour, at shallow depths and often in tidepools. It is also reported from western Australia (Sainsbury et al., 1984: 55; Gloerfelt-Tarp \& Kailola, 1984: 54; Randall et al., 1997: 36).

The overall "snowflake" or lichenous colour pattern of this species is similar to a number of other species. Gymnothorax cribroris is characterised and separated from the others by the distinctive dark brown spots on the side of the head and by the low vertebral count. It might be confused with G. margaritophorus that also has dark head spots, but which are consistently in three rows of elongate spots that radiate back from the eye, and that has a higher vertebral count (MVF 6-50-129).

Study material. Twenty specimens, $112-457 \mathrm{~mm}$ TL. AUSTRALIA: Queensland: AMS IA.4619, $334 \mathrm{~mm}$, paratype of Gymnothorax cribroris; AMS IA 5012, $252 \mathrm{~mm}$, holotype of $G$. cribroris; AMS IA.5027, $233 \mathrm{~mm}$, paratype of $G$. cribroris; AMS I.12629, 334 mm; AMS I.20209-021, 333 mm; AMS I.20463-020, 3: 390-410 mm; AMS I.20581-002, 133 mm; AMS I.20214.016, $201 \mathrm{~mm}$; AMS I.36385-002, $457 \mathrm{~mm}$; BPBM 14365, 3: 267-343 mm; CAS 87880, 2: 283-401 mm. New South Wales: AMS I.19103-044, 2: 112-230 mm; AMS I.23379-024, 343 mm; AMS I.23463.201, 409 mm.

\section{Gymnothorax longinquus (Whitley, 1948)}

\section{Long moray}

Pl. 1

Lycodontis longinquus Whitley, 1948: 73 (holotype AMS IA.6953, 720 (736) mm TL; type locality north of McKay, Queensland, Australia).

Gymnothorax sp. 1. Sainsbury et al., 1984: 54 (northern Australia). Gymnothorax sp. 1. Gloerfelt-Tarp \& Kailola, 1984: 54.

Description. A moderately large, elongate moray with tapering tail; depth at gill opening 15-24, depth at anus 18-27 in TL; anus near midbody, preanal length 2.0 . Head moderately elongate, 7.2-8.7 in TL; snout short, 2.5-6.9 in HL; upper jaw moderate, 2.4-2.9 in HL. Eye above midgape, 9.4-10 in HL. Anterior nostril in short tube; posterior nostril with raised rim, above and behind anterior margin of eye. Head pores typical, (except 1 branchial pore 

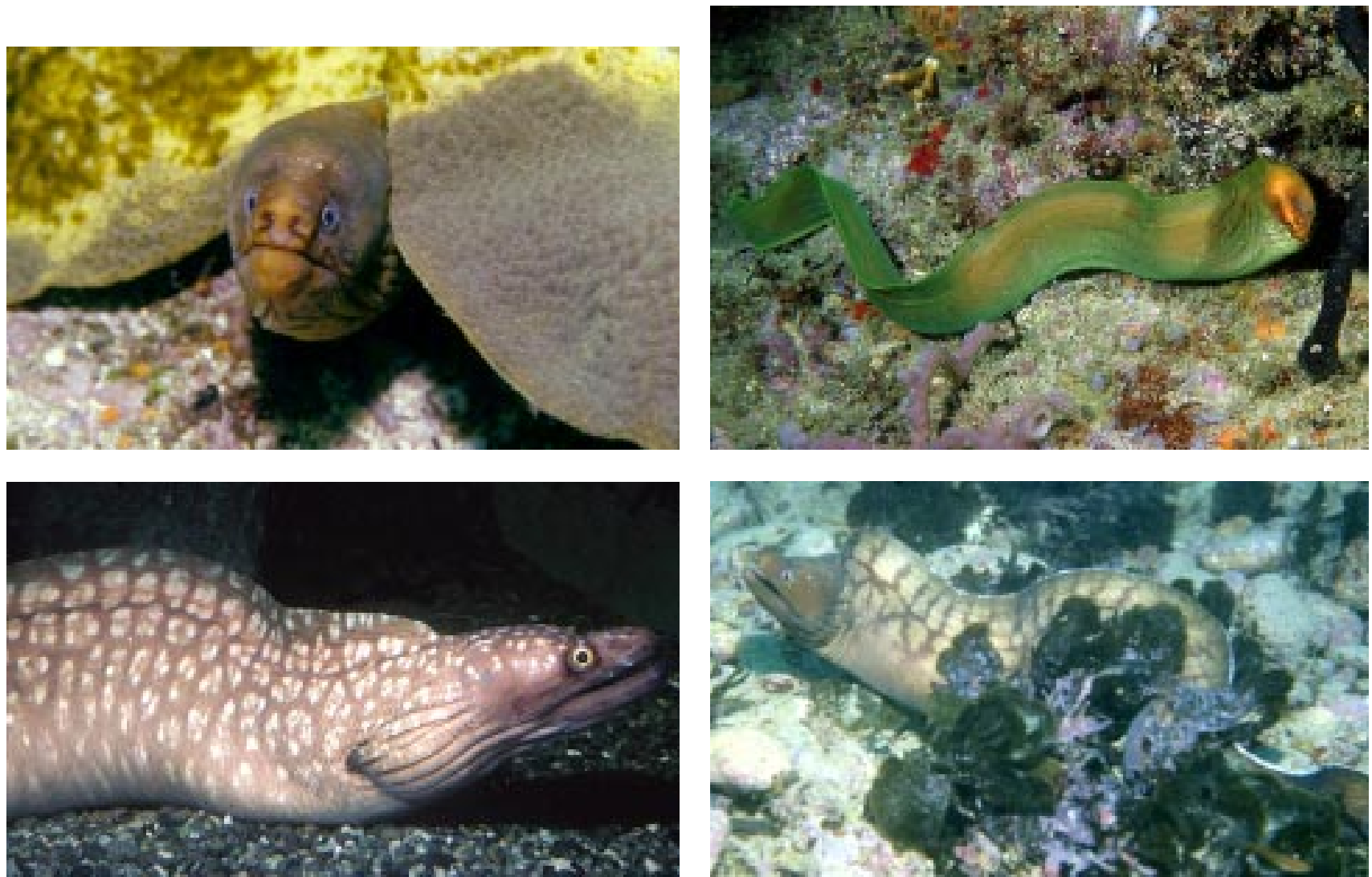

Plate 2. Upper left: Gymnothorax prasinus; WAM P.27112.001, 299 mm TL; Jervis Bay, NSW, Australia; photo by J.B. Hutchins. Upper right: Gymnothorax prasinus; Sydney, NSW, Australia; photo by R.H. Kuiter. Lower left: Gymnothorax prionodon; aquarium photograph; photo by R.H. Kuiter. Lower right: Gymnothorax woodwardi; Kalbarri, Western Australia; photo by J.B. Hutchins.

visible on holotype, and holotype and one other specimen have 7 mandibular pores); two branchial pores above and before gill opening, dorsal-fin origin above first pore. Gill opening at midside. Predorsal vertebrae 5-6, preanal vertebrae 59-61, total vertebrae 129-137; MVF 5-60-133 (6).

Teeth strong and smooth, uniserial in adults. Outer intermaxillary teeth 5-6, 3 long median fangs. Maxillary teeth $10-16$, the first 4 increasing in size, then tapering posteriorly; inner row of 1-3 long slender teeth in specimens smaller than $350 \mathrm{~mm}$. Vomerine teeth 1-7, short and sometimes hidden. Dentary teeth in single row of 15-21, the anterior 4 large, then abruptly smaller, not decreasing in size posteriorly.

Overall coloration very dark, with scattered indistinct grayish blotches on body; head paler, tail progressively darker; fins dark, with black margin. Anterior nostril with dark tip, posterior nostril with brown rim; head pores with fine brown rims. A colour photograph (Sainsbury et al., 1984: 55) shows a dark brown background with paler mottlings that were said to be gray or cream.

Notes on holotype. The holotype of Lycodontis longinquus is a large specimen (its total length, $736 \mathrm{~mm}$, is longer than Whitley's reported $720 \mathrm{~mm}$ ). It is dark and stiff with a tag through the eye, but otherwise it is in good condition, with coloration as described above. Head pores atypical, with one branchial pore and seven mandibular pores on each side. Preanal length 2.0 in TL; VF 5-59-134. Teeth strong and triangular; 3 rows intermaxillary teeth, 3 long fangs in median row; maxillary and dentary teeth uniserial (many missing); 1 short tooth visible on vomer.

Remarks. This species has not been identified since its description; it is here recognised as a valid species, characterised by its dark coloration and distinctive vertebral count. It is known from only a few specimens, the largest the $736 \mathrm{~mm}$ holotype. No mature specimens have been identified. It has been taken from scattered locations off northern Australia (from the Kimberly Region, Timor Sea, Arafura Sea, and the Gulf of Carpentaria) and from Queensland, and one specimen from a Thailand fish market (exact locality of capture uncertain). It is possibly a deepwater species (although one depth record is of $0.1-0.5 \mathrm{~m}$ ). In addition, in all preserved specimens including the holotype, the muscles are unevenly contracted, giving a curious "lumpy" surface to the body rather than the usual smooth convex appearance of morays.

Study material. Eight specimens, 258-736 mm TL. AUSTRALIA: Queensland ("north of Mackay"); AMS IA.6953, $736 \mathrm{~mm}$, holotype of Lycodontis longinquus. Gulf of Carpentaria: CSIRO C1408, $620 \mathrm{~mm}$. Northern Territory: AMS I.21943-017, $490 \mathrm{~mm}$; CSIRO T427, 344 mm; USNM 174039, 350 mm. Western Australia: WAM P.30319.106, 2: 258-299 $\mathrm{mm}$. THAILAND (fish market): URM-P 12450, $619 \mathrm{~mm}$. 


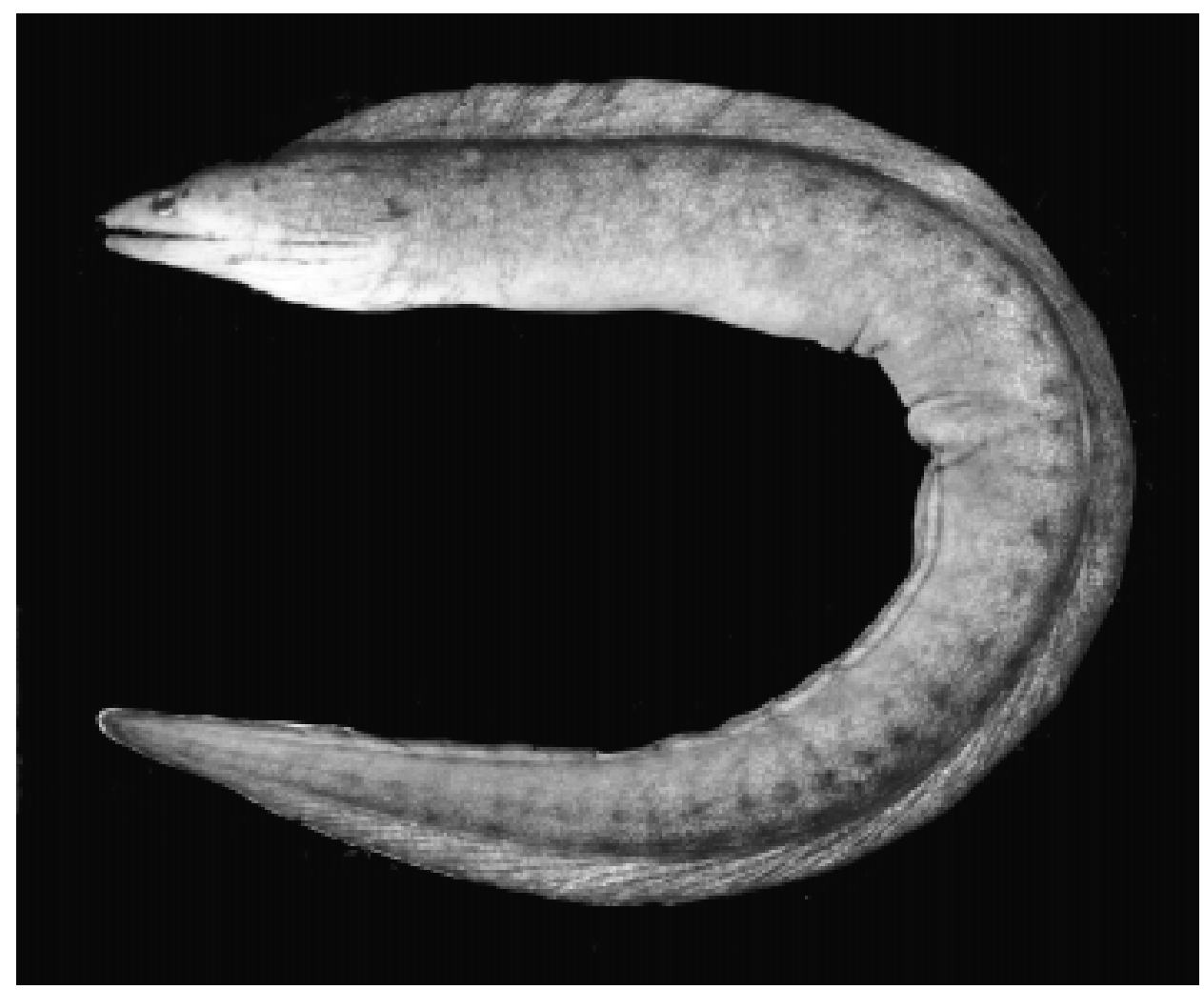

Figure 9. Gymnothorax nubilus; BPBM, 535 mm TL; Lord Howe Island; photo by J.E. Randall.

\section{Gymnothorax nubilus (Richardson, 1848)}

\section{Cloudy moray}

Fig. 9

Muraena nubila Richardson, 1848: 81, pl. 46 (figs. 6-10) (Holotype BMNH 1972.1.26.159; type locality Norfolk Island). Muraena euptera Günther, 1870: 122 (holotype BMNH 1855.8.16.50; type locality Raoul Island, Kermadec Islands).

Description. A moderately elongate moray, depth at gill opening 12-22 and depth at anus 14-22 in TL; anus before midbody, preanal length $2.1-2.3$ in TL. Head moderately elongate, 7.1-8.7 in TL; snout long and narrow, 4.7-5.7 in HL; upper jaw 2.5-2.8 in HL, lips papillose. Eye moderate, 9.3-13 in HL, above midgape and slightly closer to rictus than to snout tip. Anterior nostril in long tube; posterior nostril a pore above and behind anterior margin of eye. Head pores typical; 2 branchial pores above and before gill opening; dorsal-fin origin before first pore, closer to rictus than to gill opening. Gill opening at midside. Predorsal vertebrae 3-4, preanal vertebrae 50-54, total vertebrae 130134; MVF 4-52-132 (13).

Teeth large and smooth, uniserial in adults. Outer intermaxillary teeth 6-7 plus 3-5 tiny teeth between; 3 long median fangs (none in $680 \mathrm{~mm}$ specimen). Maxillary teeth 11-16 in main row, the first 3-4 increasing in size, then decreasing posteriorly; small specimens (to $350 \mathrm{~mm}$ ) with inner row of 1-3 long slender teeth. Vomerine teeth short, uniserial or slightly staggered, 5-14 (missing or hidden in largest specimens). Main row of 14-21 teeth on dentary, large anteriorly, then decreasing slightly in size; the anterior
4 teeth of some specimens (juveniles and females) form an inner row with the anterior outer 4-8 teeth smaller; a single row of dentary teeth in specimens $>550 \mathrm{~mm}$.

Overall coloration pale tan, with large, diffuse pale brown spots in irregular rows along base of dorsal fin and along midside, sometimes forming irregular bars on tail. Head pale tan, lower jaw, thorax and abdomen paler; head papillae in very fine brown spots forming lines on snout and top of head (similar to those marking Gymnothorax griseus [Lacepède, 1803] and G. castlei Böhlke \& Randall, 2000, but not dark and contrasting); faint dark spots mark anterior lateral-line papillae (extending to gill opening and almost to anus in some specimens). Anterior nostril brown, posterior nostril with brown rim, jaw pores in faint brown rings (not visible on pale specimens). Mouth angle dusky; dark or dusky gular streaks; gill opening dusky in some specimens. Dorsal fin patterned or dusky basally, with pale margin for entire extent or only posteriorly; anal fin dusky or dark basally with noticeable pale margin. Some specimens appear uniform medium brown due to heavy mucus, only the faint dark head spots and pale margin of the fins observable.

Notes on holotypes. The holotype of Muraena nubila is faded but has a discernible colour pattern typical of the species as described above; the lines of spots outlining the head papillae are not visible, however Richardson's figure 7 (dorsal view of the head) shows the lines of spots. Preanal length 2.2 in TL; VF 3-52-132. Teeth large and smooth; intermaxillary teeth in 3 rows, 3 long fangs in median row; maxillary and vomerine teeth uniserial; dentary teeth biserial anteriorly. 
The holotype of Muraena euptera is large and faded, otherwise it is in good condition; no overall colour pattern is visible, but dark gular folds and mouth angle can be seen, and there is a pale margin on the posterior dorsal fin and along the entire anal fin. Preanal length 2.1 in TL; VF 452-134. Teeth large and smooth; intermaxillary teeth in 3 rows, 2 long teeth in median row; maxillary dentary, and vomerine teeth uniserial. The species has seldom, if ever, been treated since its description. The holotype fits the description of G. nubilus, its proportions, vertebral count, tooth counts, and what remains of its colour pattern agree.

Remarks. Gymnothorax nubilus is said to reach $680 \mathrm{~mm}$. We did not find any mature specimens. It is known from a few specimens from Norfolk Island and the Kermadec Islands, and from New Zealand, all south of $28^{\circ} \mathrm{S}$. It was collected with rotenone at $0-15 \mathrm{~m}$.

The general colour pattern is somewhat similar to several other species. Gymnothorax nubilus is distinguished by the dark spots marking the lateral-line papillae on the head and anterior body (although the spots may be faint and easily overlooked), by the pale margin on the anal fin and posterior dorsal fin, and by its vertebral formula.

Study material. Eighteen specimens, 205-680 mm TL. NEW ZEALAND: ANSP 138635, 3: 309 ca. $590 \mathrm{~mm}$. NMNZ 21594, $680 \mathrm{~mm}$. NORFOLK ISLAND: AMS I.4319, $554 \mathrm{~mm}$; AMS I.20268-022, 9, 253-374 mm; AMS I.20270-009, 205 mm; AMS IB.5355, ca.430 mm; BMNH 1872.1.26.159, $535 \mathrm{~mm}$; holotype of Muraena nubila. KERMADEC ISLANDS: Raoul Island; BMNH 1855.8.16.50, $604 \mathrm{~mm}$, holotype of Muraena euptera.

\section{Gymnothorax obesus (Whitley, 1932a)}

\section{Obese moray}

P1. 1

Uropterygius obesus Whitley, 1932a: 329, pl. 39 (fig. 1) (holotype AMS IA.3888; type locality Montague Island, New South Wales, Australia, collected in ca. $70 \mathrm{fms}$ [128 m]).

Gymnothorax griffini Whitley \& Phillipps, 1939: 229 (new name for specimen described as Gymnothorax meleagris in Griffin, 1927: 138, pl. 10, fig. 2) (holotype AIM Ps 29.1, 1020 mm TL; type locality White Island, Bay of Plenty, New Zealand).

Muraena tuhua Griffin, 1933: 171, pl. 24 (bottom), text-fig. p. 171 (holotype AIM lost; type locality 18 miles E of Mayor Island [Tuhua], New Zealand, caught on hook and line in 80 fms [146 m] by Mr McLachlan in August 1928).

Description. An elongate, very large moray, depth at gill opening 10-17 and depth at anus 15-21 in TL; anus just before midbody, preanal length $2.1-2.2$ in TL. Head moderate, its length 8.5-9.2 in TL; snout 4.9-5.4 in HL; upper jaw 2.4-3.0 in HL; eye small, 12-21 in HL, above gape, closer to rictus than to snout tip. Anterior nostril in moderate tube; posterior nostril with short tube, well before eye margin. Head pores typical; two branchial pores above and before gill opening; dorsal-fin origin above gill opening and behind second branchial pore. Gill opening at midside. Predorsal vertebrae 9-10; preanal vertebrae 68-72; total vertebrae 166-172; MVF 10-70-169 (4).
Teeth smooth; maxillary teeth partially biserial. Intermaxillary teeth 5-6 plus 3-5 outer tiny teeth; 3 median teeth. Inner row of 3-5 long thin maxillary teeth, outer row of 16-17 small short teeth. Vomerine teeth up to 14, very small, pointed, hidden in muscle folds. Two to 4 large stout inner anterior dentary teeth, enclosed by 4-6 small outer teeth, continuing as row of 16-19 teeth of varying sizes. (Teeth based mostly on those of two paratypes; those of holotype and largest specimen difficult to see.)

Overall coloration of brown background with small, bright white irregular spots and semicircles. Snout uniform pale brown, without spots, lower jaw pale but mottled; coloration of uniform intensity and spotted pattern similar on all parts of body, abdomen, tail, and fins.

Notes on holotypes. The holotype of Uropterygius obesus is a very large, obese specimen with distinctive coloration as described above, the pattern uniform on head, body, abdomen, tail and fins. Dorsal-fin origin not obvious externally; head pores small and difficult to count. Total length described as $1515 \mathrm{~mm}$, it is now approximately 1382 $\mathrm{mm}$; because of its size, measurements taken are imprecise; VF 10-68-169. The mouth could not be opened to get tooth counts; Whitley reported 17 teeth on maxillaries and dentaries (the two paratypes have short anterior inner rows of maxillary and dentary teeth). Whitley described this species in the genus Uropterygius because the fins of the holotype are covered by flabby flesh and are not obvious externally; however, they are clearly visible in the radiograph, and can be seen externally on the two smaller paratypes.

The holotype of Gymnothorax griffini, AIM PS.29.1, is presumably in the collection at Auckland (not seen, inaccessible at present). A large specimen of $1020 \mathrm{~mm}$ TL, it was described by Griffin in 1927 under the name Gymnothorax meleagris; Whitley \& Phillipps (1939) stated that it was not the true G. meleagris of Shaw, gave it the name Gymnothorax griffini, and referred to Griffin's description and figure. The colour description and the figure strongly suggest, and other data and dentition agree, that this name is a junior synonym of $G$. obesus, as listed in Gomon et al. (1994: 207).

Of Muraena tuhua, Castle wrote (in litt, 1999): "The type could not be found, except that there is [was] a cast made." The colour was described by Griffin as "body uniform light chocolate profusely covered with pale cream spots of a great variety of sizes and forms, none of which is margined with a deeper colour." The dorsal-fin origin was said to be only slightly before the gill opening, with both fins thick and fleshy. The colour description, proportional data, tooth counts, and figure published by Griffin suggest that Muraena tuhua $=$ Gymnothorax obesus, and it was said to be from deep water (146 m) as were the types of obesus. Castle wrote to us: "I am convinced that this is obesus."

Remarks. Gymnothorax obesus is known only from the holotype, two paratypes, and one additional specimen; all are large, $730-1720 \mathrm{~mm}$, the $730 \mathrm{~mm}$ specimen is a spent female. They were taken from temperate waters of southern Australia and New Zealand south of $35^{\circ} \mathrm{S}$; the type specimens were taken in 73-128 $\mathrm{m}$ on the continental shelf off New South Wales 
and Victoria, and the fourth specimen from North Island, New Zealand, by hook and line in $128 \mathrm{~m}$. Whitley mentioned in the original description: "A living specimen in Taronga Park Aquarium, Sydney, lies with the head protruding from a heap of rocks in the usual moray fashion."

This is a valid species with an unusual colour pattern of odd-shaped, distinct small white spots on a brown background (as depicted in Whitley's figure) that is unlike and not to be confused with that of any other species.

Study material. Four specimens, 730-1720 mm TL. AUSTRALIA: New South Wales: AMS IA.3888, $1382 \mathrm{~mm}$ TL, holotype of Uropterygius obesus; AMS IA.2658, 730 $\mathrm{mm}$, paratype of U. obesus. Victoria: AMS IA.4072, 860 $\mathrm{mm}$, paratype of $U$. obesus. NEw ZEALAND: Poor Knight's Islands: NMNZ P.5492, $1720 \mathrm{~mm}$.

\section{Gymnothorax porphyreus (Guichenot, 1848)}

\section{Lowfin moray}

Fig. 10

Muraenophis porphyreus Guichenot in Gay, 1848: 342, pl. 11 (fig. 2) (no type known; type locality Juan Fernandez Island, Chile). Muraena chilensis Günther, 1871: 674 (holotype BMNH 1871.9.13.881; type locality Chile).

Gymnothorax Wieneri Sauvage, 1883: 161 (2 syntypes, MNHN 4868; type locality Chile or Peru).

Gymnothorax obscurirostris Rendahl, 1921: 62 (holotype NRM 7103; type locality Easter Island).

Description. A large moray, elongate when small, large specimens stout, depth at gill opening 12-20 and depth at anus 13-30 in TL; anus near midbody, preanal length 1.92.3 in TL. Head moderate to short, its length $7.3-10.5$ in TL; snout short and broad, 4.6-6.1 in HL; jaws moderate, upper jaw 2.0-3.0 in HL. Eye above midgape, slightly closer to rictus, 9.7-19 in HL. Anterior nostril in short tube; posterior nostril above and before eye, raised or in short tube with flared crenulate margin. One $(925 \mathrm{~mm})$ specimen with ridge of 4 small rounded flap-like projections on nape between eyes. Head pores typical; 2 branchial pores, the second pore just above gill opening; dorsal-fin origin above or before first pore. Gill opening a diagonal slit at midside. Predorsal vertebrae 5-8, preanal vertebrae 57-62, total vertebrae 137-144; MVF 6-59-140 (26).

Teeth strong, triangular, smooth, partially biserial, moderate in number. Main row of outer premaxillary teeth usually 6 , with 3-12 small outer teeth present in both small and large specimens; usually 3 caniniform teeth on midline. Inner row of 1-6 long slender maxillary teeth anteriorly, outer row of 10-18 shorter stout teeth changing little in size. Vomerine teeth short and sharp, usually in single row of 6-12 teeth (the $925 \mathrm{~mm}$ specimen has 24 biserial teeth). Dentary teeth 18-27, the first 4-7 large and increasing in size, then abruptly smaller, changing little in size; outer row of 2-15 short pointed teeth flanking main row anteriorly, extending back in some specimens.

Overall colour dark grey or brown with darker mottling, head, body and fins with similar coloration; nostrils and head pores noticeably dark. Snout dark, mouth angle dark, gill opening dusky or dark, but not in a defined black blotch. Fins of small specimens $(<250 \mathrm{~mm})$ with pale margin or pale posteriorly; those of larger specimens with body coloration.

Notes on types. There are no type specimens for species described by Guichenot, and his description of Muraena porphyreus was very brief; species' identification has long been based on his colour figure on pl. 11 (fig. 2), which depicts a reddish brown moray upon which yellow marbling and small dark brown spots are superimposed. (The dorsal-fin origin is depicted as being far behind the gill opening, and prominent external upper and lower jaw bones are visible, not characters of the species.) Although no type specimens for Muraenophis porphyreus are known to exist (Bauchot et al., 1993), we are hesitant to designate a neotype as an end in itself.

The holotypes of Muraena chilensis and Gymnothorax obscurirostris, and the two syntypes of Gymnothorax Wieneri have been re-examined, and data are included in the above description; vertebral counts are 8-60-137 for $M$. chilensis], 6-59-138 for G. obscurirostris], and 6-62-137 and 5-60-138 for syntypes of G. Wieneri. Randall \& McCosker (1975) placed Gymnothorax obscurirostris Rendahl in the synonymy of G. porphyreus on the basis of its described morphology and coloration, but were unable to examine the holotype. We have examined the holotype, which is in good condition, and determined that it is clearly a specimen of $G$. porphyreus.

Remarks. Gymnothorax porphyreus grows to a large size; our largest specimen is $1030 \mathrm{~mm}$. Four of the study specimens are females (395-803 $\mathrm{mm}$ ), the $803 \mathrm{~mm}$ specimen ripe with $1.4 \mathrm{~mm}$ eggs. None are mature males. The species frequents cool waters of the eastern Pacific off Chile and Peru and is found at Easter Island, the Kermadecs, Norfolk and Lord Howe Islands, and waters of New Zealand, all south of $25^{\circ} \mathrm{S}$; it was caught by rotenone, hook and line, and spear, at shallow depths recorded to $13 \mathrm{~m}$.

Gymnothorax porphyreus was treated by Randall \& McCosker (1975: 23) who determined and listed its synonyms; the described species were all from the eastern Pacific, but they found no differences between specimens from that area and from Lord Howe Island. Our specimens from Norfolk Island, the Kermadec Islands and New Zealand show no differences from other G. porphyreus. Some of the specimens from New Zealand had been identified by various museum personnel as G. griffini Whitley \& Phillipps, a species that we and Castle have placed in the synonymy of $G$. obesus. The identity of $G$. griffini has not been confirmed, but the description of its colour and its posterior nostril fits that of G. obesus rather than that of G. porphyreus.

The overall coloration is similar to that of G. flavimarginatus, which is a tropical species with the gill opening in a defined black blotch, the head pores not noticeably dark, and a pale (yellow-green) margin on the posterior fins. The overall coloration is also similar to that of G. parini, which is found in cool southern waters of the Indian Ocean, but that has conspicuous pale margins on the fins.

Study material. Forty-five specimens, $61-1030 \mathrm{~mm}$ TL. CHILE: BMNH 1871.9.13.881, $345 \mathrm{~mm}$, holotype of Muraena chilensis. EASTER ISLAND: NRM 10986, $259 \mathrm{~mm}$, holotype of Gymnothorax obscurirostris; CAS 24762, 210 mm. Juan Fernandez Island: ANSP 122775, 850 mm. CHILE 


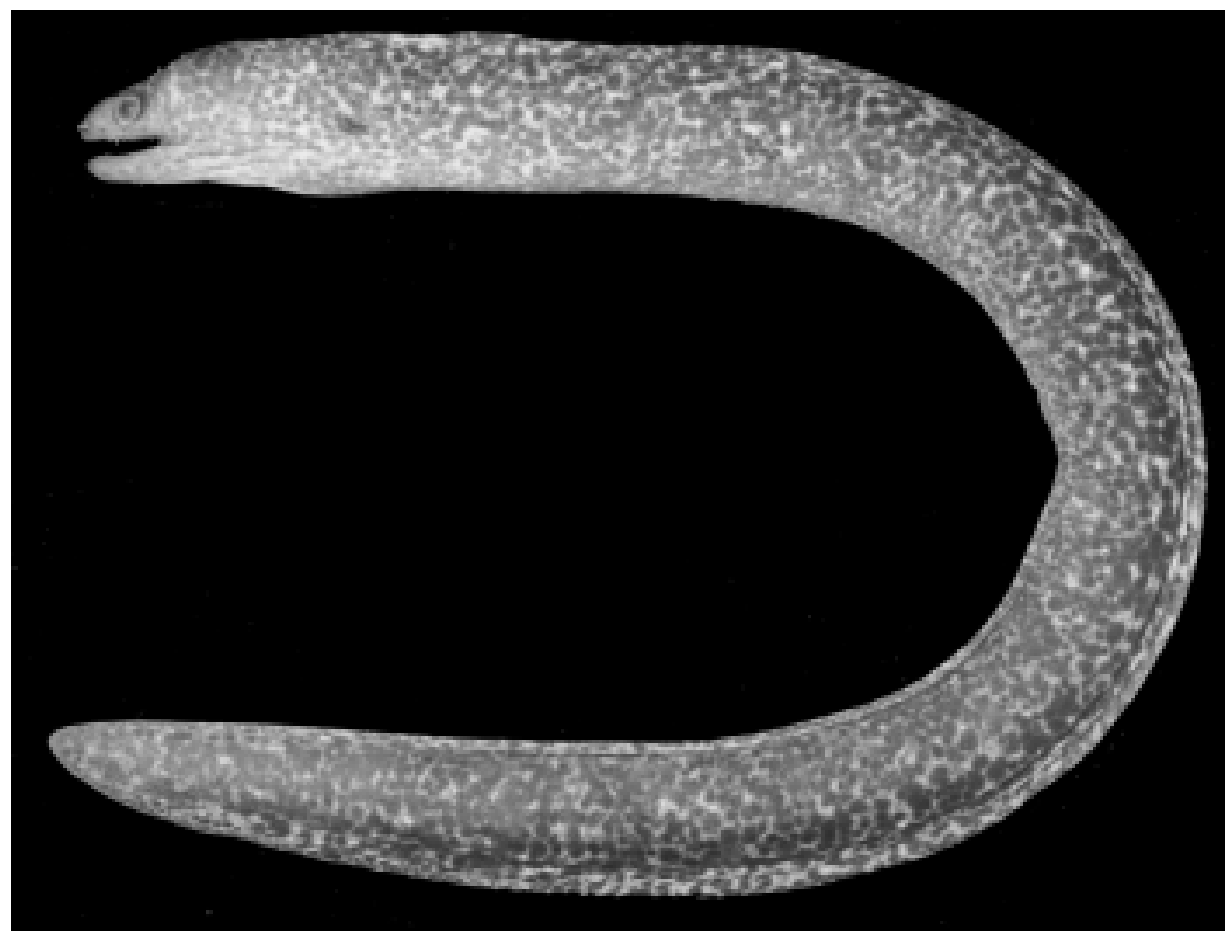

Figure 10. Gymnothorax porphyreus; 315 mm TL; Easter Island; photo by J.E. Randall.

or PERU: MNHN 4868, 2: 760-765 mm, syntypes of Gymnothorax Wieneri. PERU: Lobos de Afuera Island: SU 37399, 15: 61-400 mm. RAPA: Haurei Bay: AMNH 56170, 203 mm. NEW ZEALAND: Bay of Plenty: NMNZ 2720, 1030 mm; NMNZ 36757, 3: ca. 935-1065 mm; NMNZ 36458, 2: ca. 725-925 mm. NORFOLK ISLAND: NMNZ 26911, 760 mm. LORD HOWE ISLAND: AMS I.17368-022, 449 mm; AMS 17368-043, 2: 301-404 mm. KERMADEC ISLANDS: NMNZ 4509, $595 \mathrm{~mm}$; NMNZ 7019, $945 \mathrm{~mm}$; NMNZ 7020, 803 mm; NMNZ 28615, 99 mm; NMNZ 28616, 3: 89-154 mm; NMNZ 35117, 202 mm; NMNZ 35144, 3: 245-403 mm; NMNZ 35150, ca. 610 mm. AUSTRALIA: New South Wales: AMS I.23379-002, $827 \mathrm{~mm}$.

\section{Gymnothorax prasinus (Richardson, 1848)}

Southern green moray

$$
\text { Pl. } 2
$$

Muraena prasina Richardson, 1848: 93 (holotype BMNH uncatalogued; type locality Bondi Bay, Sydney, Australia).

Gymnothorax jacksoniensis Bleeker, 1863: 450 (holotype RMNH 3780; type locality Port Jackson, NSW, Australia).

Gymnothorax maculaepinnis Bleeker in Steindachner, 1866: 473 (syntypes missing; type localities Port Jackson, Macassar, Hong Kong [the latter two questionable]).

Muraena callorhyncha Günther, 1870: 122 (holotype BMNH 1861.5.18.7; type locality Freemantle, Western Australia).

Muraena krulli Hector, 1877: 468, pl. 8 (fig. 107a) (holotype lost; type locality Bay of Islands, New Zealand).

Gymnothorax leecote Scott, 1965: 54, fig. 1 (holotype QVM 1964.5.15; type locality George Rock, N of St. Helens, Cornwall, Tasmania, in crayfish net set at $10 \mathrm{fms}$.)

Verdithorax prasinus.-Whitley, 1931: 311 (new genus, orthotype Muraena prasina Richardson, 1848).
Notorabula callorhyncha.-Whitley, 1934: 154 (new genus, orthotype Muraena callorhyncha Günther, 1870).

Description. A large, elongate moray with tapering tail, depth at gill opening 12-20 and depth at anus 15-23 in TL; anus usually near or before midbody, preanal length 1.92.2. Head short, 8.0-10 in TL; snout moderately short, its length 5.0-6.4 in HL; upper jaw moderate, 2.4-3.0 in HL; eye small 10-15 in HL, above midgape. Anterior nostril in moderate to long tube; posterior nostril above and behind anterior margin of eye, raised or in short tube with crenulate rim. Head pores typical; 2 branchial pores, second pore just above gill opening; dorsal-fin origin above first pore, closer to gill opening than to rictus. Predorsal vertebrae 4-7, preanal vertebrae 56-60, total vertebrae 134-140; MVF 5-58-137 (16).

Teeth stout and smooth; maxillary teeth biserial anteriorly. Main intermaxillary teeth 7-10, plus 1-6 small outer teeth; 3 stout median teeth. Short inner row of 2-6 (usually 3-4) moderately long maxillary teeth in specimens of all sizes; outer row of 10-18 moderate teeth. Vomerine teeth 9-14, small and usually uniserial (19 were counted in the holotype, the first 11 teeth biserial, possibly an artifact of preservation). Usually 4 large inner dentary teeth, outer row of 19-25 teeth, the anterior 3-6 small and enclosing the large teeth.

Body and fins dark brown, usually covered with pale (greenish) mucus. Head pale brown, with median dorsal pale streak bordered on each side by dark brown streak from snout to behind eye. Nostrils and head pores dark, contrasting with head coloration; anterior nostril dark around base, posterior nostril dark brown; head pores dark, sometimes with white rims bordered by dark brown pigment. Fins dark, tip of tail sometimes pale. In life, body colour brown to dirty yellow to green; green colour may be due in part to a heavy mucous coating. 
Notes on types. Muraena prasina was described from a "dried skin" of 23.5 inches, collected by a Mr McGillivray, and from notes made at the time of capture. The holotype was located in 1995 in the BMNH dry collection; the head and the skin of the left side had been mounted on a strip of wood, so that it appeared to be a whole stuffed specimen; the base was labelled Muraena afra (Günther's identification), but the original name and locality were pencilled on the bottom of the stand. It is dark overall, with no visible pattern, the anus not discernible (the anal fin had been removed). Teeth are in good condition and countable (but many are missing); apparently 3 rows of intermaxillary teeth, 3 long median fangs; uniserial maxillary teeth (plus one inner tooth); Vomerine teeth numerous and partially biserial; dentary teeth biserial.

The holotype of Gymnothorax jacksoniensis was received from the Australian Museum. It is a large dark specimen with black nostrils and black head pores, and has the dorsal and anal fins dissected for their entire length, as is characteristic of many Bleeker moray types. Preanal length 1.9 in TL; VF 5-58-134. Intermaxillary teeth in 3 rows,median row of 3; maxillary and dentary teeth biserial anteriorly; vomerine teeth uniserial. Günther included this species under his catch-all listing of Muraena afra (an eastern Atlantic species); it has more recently been included in the synonymy of Gymnothorax prasinus by Paxton et al. (1989: 131).

Gymnothorax maculaepinnis was named in a paper by Steindachner on the fishes of Port Jackson. It listed three specimens of the moray from Port Jackson, Macassar and Hong Kong, which were presumably in the Vienna Museum at the time. The brief account followed the listing of G. prasinus; the single difference mentioned was that this species possessed a second row of 1-3 palatine teeth. A search was made at NMW in 1997 for specimens labelled as G. maculaepinnis or as $G$. prasinus, but none were found under either of those names; the types are considered to be missing. The inclusion of the species in the synonymy of Gymnothorax prasinus seems justified (for the Port Jackson specimen), since the two species were separated only by differences in the palatine (maxillary) teeth, a variation common in morays.

The holotype of Muraena callorhyncha is dark, with a median pale streak bordered by brown bands on each side which extend from the snout tip to the eye, and it has dark head pores. Dorsal-fin origin behind gill opening; preanal length 2.0 in TL; VF 11-60-137. Intermaxillary teeth in 3 rows, median row of 3 teeth; maxillary and dentary teeth biserial anteriorly; vomerine teeth not seen. The holotype exhibits the characters of $G$. prasinus except for the origin of the dorsal fin; it is placed in the synonymy of G. prasinus, as listed in Paxton et al. (1989: 131), the dorsal-fin origin considered to be anomalous.

The holotype of Muraena krulli "with little doubt does not exist, along with many of Hector's types" (Castle, in litt., 1999). The "31.5 inch" specimen was briefly described as uniform dark brown without any light or dark markings, and illustrated by a line drawing. It was put in the synonymy of Gymnothorax prasinus by Griffin (1926: 539), who presumably had access to the holotype at the time; the name remains there.

The holotype of Gymnothorax leecote Scott (1965) is in the Queen Victoria Museum, Launceston, Tasmania, and was examined by the junior author. The $808 \mathrm{~mm}$ TL specimen (original number 123) is identifiable as a specimen of $G$. prasinus. It is dark brown and has the dentition, morphometry, and vertebral formula (5-59-138) appropriate for the species.

Remarks. The largest specimen we examined is $855 \mathrm{~mm}$; none of the specimens is mature. It is a well-known species in the south temperate waters of Australia and New Zealand, and is said to be common off New Zealand, southeastern and southwestern Australia, and taken at depths to $40 \mathrm{~m}$. (A specimen of G. prasinus reported from Cape Radstock in far western South Australia [Glover \& Branden, 1983] is presumed to have been extralimital [Hutchins, 1994: 59].) It is readily recognised by its uniform brown coloration (in preservative) with contrasting snout streak, dark nostrils and head pores. It is commonly known as the "Green moray" in Australia and the "Yellow moray" in New Zealand. We propose that it be commonly known as the "Southern green moray" so as to avoid confusion with the Green moray of the Caribbean ( $G$. funebris) and the Green or Chestnut moray of the eastern Pacific (G. castaneus).

Whitley (1931), without explanation, described the new genus Verdithorax to include Muraena prasina and M. krulli. It was soon synonymised with Gymnothorax. Whitley (1934), with minor explanation, described Notorabula to include Muraena callorhyncha, based on Ogilby's (1907) placement of that species in Rabula, a genus where it also did not belong. Notorabula, like Verdithorax, was soon synonymised with Gymnothorax.

Study material. Thirty-nine specimens, $155-855 \mathrm{~mm}$ TL. NEW ZEALAND: NMNZ 33986, $790 \mathrm{~mm}$. AUSTRALIA: New South Wales: AMS I.16237-013, 326 mm; AMS I.16250-026, 304 mm; AMS I.16861-013, 483 mm; AMS I.19943-020, 299 mm; AMS I.21774-034, 2: 173-583 mm; AMS I.28738024, 6: 280-700 mm; AMS I.31124-006, 6: 70-304 mm; ANSP 135449, 3: 142-338 mm; ANSP 138735, 8: 222-450 $\mathrm{mm}$; BMNH uncatalogued, ca.610 mm (mounted half-skin), holotype of Muraena prasina; CAS 87884, 2: 350-446 mm; NMW 61526, 2; RMNH 3780, $572 \mathrm{~mm}$, holotype of Gymnothorax jacksoniensis. Victoria: NMV R.8085, $855 \mathrm{~mm}$. Western Australia: BMNH 1861.5.18.7, $476 \mathrm{~mm}$, holotype of Muraena callorhyncha. Tasmania: QVM 1964: 5: 0015, 815 $\mathrm{mm}$, holotype of Gymnothorax leecote.

\section{Gymnothorax prionodon Ogilby, 1895}

Indo-Pacific spotted moray

Pl. 2

Gymnothorax prionodon Ogilby, 1895: 720 (holotype AMS I.3324, in the Old Collection of Australian fishes; type locality Port Jackson, NSW).

Muraena mieroszewskii Steindachner, 1896: 222 (holotype NMW 61642; type locality Kobe, Hiago and Nagasaki, Japan).

Gymnothorax leucostigma Jordan \& Richardson, 1909: 174, pl. 68 (holotype FMNH 52124; type locality Takao, Formosa).

Gymnothorax nirosus Tanaka, 1918: 51 (holotype ZUMT 8628 [lost]; type locality Nagasaki Fish Market, Japan).

Muraena shirleyi Griffin, 1933: 172, pl. 24 (top), text-fig. p. 173 (holotype AIM Ps.289.1, type locality Mokohinau Islands, New Zealand).

Lycodontis wooliensis Whitley, 1968: 33, pl. 8 (fig. 1) (holotype AMS IB.7941; type locality off Wooli, 2952'S $153^{\circ} 20^{\prime} \mathrm{E}$, NSW, 
Australia, trapped in deep water).

Serranguilla prionodon.-Whitley \& Phillipps, 1939: 228 (new genus, type species Gymnothorax prionodon Ogilby, 1895).

Description. A large moray with tapering tail; depth at gill opening 11-17 and depth at anus 13-21 in TL; anus before midbody, preanal length 2.0-2.2. Head elongate, 6.8-8.0 in TL; snout long and narrow, its length 4.6-6.8 in TL, head bulbous behind; jaws long, upper jaw length 2.1-3.0 in HL. Eye small, above midgape, its diameter 10-14 in HL. Anterior nostril in long tube; posterior nostril above anterior margin of eye, with raised rim. Head pores typical; 2 branchial pores above and before gill opening; dorsal-fin origin above or before first branchial pore. Gill opening at midside. Predorsal vertebrae 4-7; preanal vertebrae 53-58; total vertebrae 135-142; MVF 6-54-138 (8).

Dentition uniserial; teeth smooth (not serrate), few, long and slender, frequently broken or missing. Intermaxillary teeth 6-6, 0-3 long median teeth (absent in adults). Maxillary teeth $7-15$, decreasing moderately in size posteriorly. Vomerine teeth $0-8$, short and hidden in muscle folds. Dentary teeth tall and slender, 11-23, decreasing in size posteriorly.

Background colour medium brown, with small to moderate pale spots, the pattern highly variable. Small spots on dorsal head, lower jaw uniform tan; thorax and abdomen spotted in large specimens. Body spots small, ocellated, and moderately separated in small specimen (the holotype), becoming larger and divided into segments in larger specimens, sometimes fewer, more widely separated, and ocellated on tail. Both dorsal and anal fins slightly dark, with 1-2 rows of spots, frequently a row on margin of fins some of which may be joined, but not forming a continuous pale margin on fins. Mouth angle and gill opening dusky; dark gular folds present. Color photos in Coleman (1983: 41) and Kuiter (1993: 33) show a reddishbrown background with small pale spots dorsally on the head, larger and extending ventrally on the body, and slightly smaller, more widely spaced, and ocellated on the tail. In the largest $(866 \mathrm{~mm})$ specimen from New Zealand the spots were separated and ocellated on the entire body and tail similar to the spots on the holotype.

Notes on types. The holotype of Gymnothorax prionodon is moderately small, in poor condition, its jaws dissected and broken. It is faded brown, with small, pale, well-spaced ocellated spots visible on the body and tail, and a row along the base of the dorsal fin. Preanal length 2.2 in TL; VF 658-140. Teeth mostly missing (sockets visible); the few remaining show a basal knob but are not serrate (as described by Ogilby); subsequent descriptions of the species note "None of teeth serrate" (Griffin, 1926: 538). Intermaxillary teeth in 2 outer rows, no median teeth; maxillary and dentary teeth uniserial, no vomerine teeth (a few depressions could be sockets).

The holotype of Muraena shirleyi was not seen by us but was previously examined by Castle (in litt., 1999) who provided its catalogue number, length $(1030 \mathrm{~mm})$, and VF (4-53-136?). Its proportions, counts, dentition, and colour description, as well as Griffin's figure on plate 24 (top), indicate it is a junior synonym of Gymnothorax prionodon. Griffin himself said "At first sight it might be taken for a pale variety of $G$. prionodon, but there are... differences..." Griffin had previously (1926) described a $714 \mathrm{~mm}$ specimen of $G$. prionodon from Mokohinau Islands (northeastern North Island, NZ).

The holotype of Lycodontis wooliensis is a moderately large male specimen with a tapering tail and is in good condition. It is medium brown, the head spotted dorsally, body with large, irregular pale spots which are divided into segments; dorsal fin spotted, anal fin spotted basally with darker margin (adult coloration). Total length, $773 \mathrm{~mm}$ (longer than Whitley's $740 \mathrm{~mm}$ ); preanal length 2.0 in TL; VF 6-54142. Intermaxillary teeth in 2 outer rows, no median teeth; maxillary, vomerine, and dentary teeth uniserial.

The identity of Gymnothorax prionodon has not been well documented, and we found few specimens in collections. Some underwater photographs have been identified as that species (Coleman, 1983: 41; Castle, unpublished). Studies of those specimens and comparison with the holotypes of several whitespotted species described from the northwestern Pacific suggest it is conspecific with several described species, all from deep temperate waters: Muraena mieroszewskii and Gymnothorax nirosus from Japan, Gymnothorax leucostigma from Taiwan, and Lycodontis wooliensis from New South Wales. Holotypes of these have been recently re-examined, data recorded and included in the description above. They are all larger specimens, and have the large complex spots of adults as described above and as depicted in recent photographs of Gymnothorax prionodon. The holotype of Gymnothorax mieroszewskii is a large specimen with excellent colour pattern and VF of 5-54135; that of G. leucostigma has a similar colour pattern and VF of 5-53-136; the holotype of G. wooliensis is described above. Gymnothorax nirosus was described in Japanese by Tanaka in 1918, and later (Tanaka, 1931: 21) listed (as G. nivosus [sic]) as a junior synonym of $G$. mieroszewskii. The holotype has been declared lost; the name is retained in the synonymy of $G$. prionodon based on Tanaka's synonymy of $G$. nirosus with G. mieroszewskii.

Remarks. Gymnothorax prionodon is said to reach 1000 mm (Coleman, 1983: 41). Our largest study specimen is $866 \mathrm{~mm}$; the $498 \mathrm{~mm}$ specimen is a developing female, the $866 \mathrm{~mm}$ a male. Our specimens are from moderate to deep waters (recorded 37-128 m) south of the equator, off southern Queensland and NSW on the east coast of Australia, and off New Zealand. North of the equator, it is known from off northern Taiwan and Japan.

Lycodontis johnsoni Smith, 1962, taken off the east coast of Africa and in the Red Sea, is very similar to G. prionodon, but there are subtle differences in adult coloration; juveniles of both have separated, ocellated pale spots, but adults of johnsoni have numerous closely-set white spots separated by brown reticulations. Another similar species is G. kidako (Temminck \& Schlegel, 1846), also from the northwestern Pacific and Queensland, and the closely related G. niphostigmus Chen, Shao \& Chen, 1996, from Japan and Taiwan; they are readily separated by the colour pattern of larger "snowflakelike" spots, a prominent pale margin on the anal fin, and more vertebrae (MVF 5-55-141 and 4-54-141 respectively).

Gymnothorax prionodon is the type species for the genus Serranguilla Whitley \& Phillipps, the new genus that they based on Ogilby's statement that it possessed serrate teeth, 
and the common name applied to this species was the "sawtooth moray." However, the holotype and all specimens examined do not possess serrate teeth.

Study material. Eight specimens, 315-886 mm TL. JAPAN: NMW 61642, $832 \mathrm{~mm}$; holotype of Muraena mieroszewskii. TAIWAN: ANSP 176116, 2: 482-535 mm; FMNH 52124, 790 mm, holotype of Gymnothorax leucostigma. AUSTRALIA: New South Wales: AMS I.3324, 315 mm; holotype of Gymnothorax prionodon; AMS IB.7941, $773 \mathrm{~mm}$, holotype of Lycodontis wooliensis. Queensland: QM I 9153, 498 mm. NEW ZEALAND: Bay of Plenty: NMNZ 4857, $866 \mathrm{~mm}$.

\section{Gymnothorax woodwardi McCulloch, 1912}

Woodward's moray

\section{Pl. 2}

Gymnothorax woodwardi McCulloch, 1912: 80, fig. 1 (holotype WAM P.13263.001; type locality Pelsart Island, Western Australia).

Description. A moderately large moray, depth at gill opening 12-24 and depth at anus 14-23 in TL; anus before midbody, preanal length $2.1-2.3$ in TL. Head 7.7-8.6 in TL; snout elongate, 4.4-5.4 in HL, upper jaw 2.0-2.6, and eye 9.3-11 in HL, slightly closer to rictus. Anterior nostril in long tube; posterior nostril a pore above anterior margin of eye. Head pores typical; 2 branchial pores above and before gill opening; dorsal-fin origin above or before first pore, closer to rictus than to gill opening. Gill opening at midside. Predorsal vertebrae 4-5; preanal vertebrae 56-58; total vertebrae 134-141; MVF 4-57-137 (5).

Teeth long and smooth, very slender and sharp, uniserial in adults. Peripheral intermaxillary teeth 6 plus $0-4$ tiny teeth between, present in small specimens, not visible in specimens greater than $400 \mathrm{~mm} ; 3$ very long stiletto-like median teeth. Maxillary teeth 9-14, decreasing in size posteriorly, plus 1-2 longer inner teeth in specimens smaller than $300 \mathrm{~mm}$. Vomerine teeth 8-11, short and rounded, sometimes staggered. Main row of 12-18 dentary teeth, large anteriorly and decreasing in size posteriorly, sometimes a few tiny outer teeth anteriorly.

Body colour pale tan with brown reticulum outlining pattern of about 3 rows of large polygonal pale spots dorsally, pale and unpatterned ventrally. Head pale, with dark or dusky gular streaks and mouth angle; pale and unpatterned ventrally. Dorsal fin patterned or dusky basally, with pale margin posteriorly; anal fin dark basally with narrow pale margin. A colour photograph of a live specimen appears in Kuiter (1997: 31).

Notes on types. The holotype, WAM P.13263.001, was not seen by us; the data presented in the original description were based on the holotype and four paratypes. We examined three of the four paratypes, now at AMS, and data were taken. They have coloration similar to that depicted in figure 1 of the original description. The vertebral formulae of the three paratypes examined are: AMS I.7235, VF 4-56134, and AMS I.12224-12225, VF 4-56-137 and 4-58-135.
Remarks. This species is fairly common off western Australia but has not been taken elsewhere. The largest known is $577 \mathrm{~mm}$, but no mature specimens were seen. It inhabits offshore waters; one specimen was reported from $182 \mathrm{~m}$. It is best identified by its colour pattern of pale polygons on the dorsal half of its body and by its very slender, stiletto-like teeth.

Study material. Eleven specimens, 302-577 mm TL. Western Australia: CAS 87879, 245 mm. Cape Naturaliste-Geraldton: AMS E.2473, 302 mm. Houtman Abrolhos: AMS I.7235, 310 mm, paratype of Gymnothorax woodwardi. Nanduran: AMS IB.1635, $575 \mathrm{~mm}$. Pelsart Island: AMS I.12224, 420 mm, and AMS I.12225, ca. 577 mm, paratypes of Gymnothorax woodwardi. Rottnest Island: AMS I.20240-001, 2: 330-374 mm. Swan River: AMS I.13147, 424 mm. Perth: CAS 131886, 2: 495-575.

\section{Notes on additional Australian and New Zealand muraenids}

\section{Type specimens}

Muraena helena australiae Richardson, 1848: pl.49 (figs. 1-6). Holotype BMNH 1847.5.10.16, 25 in. (594 mm) TL; Australia.

\section{= Muraena helena Linnaeus, 1758}

The name Muraena helena australiae appears in the caption for pl. 49 following Richardson's description of Muraena helena from Gibraltar; measurements are presented for the specimen from Australia (which agree with the designated holotype), and for a 30 inch specimen from Gibraltar. Counts, proportions, dentition, and vertebral counts are typical for $M$. helena from the eastern Atlantic and Mediterranean. The locality of Australia is considered to be erroneous. Supporting this is the fact that the original catalogue entry lists no locality; on the same page two other morays are listed with no locality: M. polyzona, known from the Indo-Pacific, and M. pavonina, originally described without a locality and considered by early authors (Richardson, 1848; Günther, 1870) to be from the "South Seas", but later discovered (Böhlke et al., 1989: 199) to most probably have been collected at Ascension Island in the Atlantic Ocean. Ogilby (1907: 11) unnecessarily created the replacement name Muraena vorax for Muraena helena australiae Richardson, and we include vorax within the synonymy of $M$. helena Linnaeus.

Muraena cancellata Richardson, 1848: 87, pl.46 (figs. 15). BMNH, 3 syntypes, 17.5 in. TL (not found); Western Australia, Surgeon Bynoe; Cape Upstart; Sumatra, College of Surgeons. (from Richardson).

= Gymnothorax undulatus (Lacepède, 1803)

None of the syntypes of Muraena cancellata can be located (one must have been extensively dissected to provide Richardson's description of organs, osteology, and vertebral counts). The colour pattern described and illustrated, as well as the tooth and vertebral count of 4-50-127 given by Richardson, fit Gymnothorax undulatus with which it has long been synonymised. 
Gymnothorax chalazius Waite, 1904: 145, pl.17, fig. 2. Holotype AMS I.5479, 415 (413) mm TL; Lord Howe Island; E.R. Waite and A.R. McCulloch.

= Gymnothorax eurostus (Abbott, 1861)

The holotype of Gymnothorax chalazius is relatively stout and of moderate size, dark brown overall, with faded but typical colour pattern of about 4 rows of dark spots dorsally, and small pale spots overall, visible on head, body and fins. Total length $413 \mathrm{~mm}$; preanal length 2.3 in TL; VF 6-48124. Teeth numerous, short and stout; intermaxillary teeth in 5 rows across with 2 in median row; maxillary and dentary teeth biserial; vomerine teeth uniserial. Gymnothorax chalazius was put in the synonymy of $G$. eurostus by Randall \& McCosker (1975: 25); the holotype and other specimens identified as $G$. chalazius at AMS are specimens of $G$. eurostus. (AMS I.6271, 315 mm; Lord Howe Island; "Old Collection", registered before Sept. 1903, may be the paratype mentioned as "a second example... $320 \mathrm{~mm} .$. ")

Gymnothorax dakini Whitley \& Colefax, 1938: 285, pl. 14 (fig. 2). Holotype AMS IA.6990, 576 mm TL (lost); Nauru, Gilbert Islands; Prof. W.J. Dakin; 1934.

\section{= Gymnothorax, nomen dubium}

The holotype of Gymnothorax dakini cannot be located in the Australian Museum. It was described as a large moray, yellow brown mottled with dark, the edge of the fins pale dirty-yellow, with gill opening and mouth angle not dark. Total length $576 \mathrm{~mm}$; calculated preanal length 2.4 in TL. Teeth smooth; vomerine teeth "a well developed row on each side." The proportional data, colour of the body and fins, and biserial vomerine dentition suggest that it might be Gymnothorax flavimarginatus, a common tropical species but which has the gill opening in a dark blotch. The name is therefore considered to be a nomen dubium.

Muraena elegantissima Kaup, 1856: 67. Holotype MNHN B.2466, 8.11 in. (195 mm) TL; Australia?; J.S.C.Dumont, Austrolabe Expedition; 1826-1829.

\section{= Gymnothorax pictus $(\mathrm{Ahl}, 1789)$}

The holotype is small, shrivelled, and difficult to measure; it is pale, with 3 rows of dark spots along body, including abdomen; head and lower jaw spotted. Total length $195 \mathrm{~mm}$; preanal length 2.1 in TL; VF 9-57-131. Intermaxillary teeth in 3 rows, 1 short tooth in median row; maxillary and dentary teeth uniserial; vomerine teeth staggered. Coloration, proportions, and vertebral count support its identity as Gymnothorax pictus.

Gymnothorax garsiae Whitley \& Colefax, 1938: 286, pl. 14 (fig. 3). Holotype AMS IA.7171, 129 mm TL (lost); Gilbert Islands, on reef flat; Prof. Harvey Sutton; March 1937.

\section{= Gymnothorax, nomen dubium}

The holotype cannot be found in the Australian Museum. It was described as dark uniform brown to black, with a narrow edge of white around tip of tail. Total length $129 \mathrm{~mm}$; preanal length calculated as 2.2 in TL. Teeth long, acute fangs, largest anteriorly, an inner row of 4 maxillary teeth. This generalised description of a very small specimen provides few clues to its identity, and the name must be considered a nomen dubium.

Anarchias insuetus Whitley, 1932b: 272, fig. 1. Holotype AMS IA.4448; 185 mm TL; Australia, Queensland, Low Isles off Port Douglas; G.P. Whitley, Boardman.

\section{= Uropterygius, nomen dubium}

The holotype is small and completely faded with no discernible pattern; there is a large hole behind the anus. Preanal length 2.2 in TL; VF 98-104-115. Teeth numerous, long and hooked back; intermaxillary and maxillary teeth continuous, with an inner row of fewer well-spaced teeth and an outer row of many small teeth; vomerine teeth long and well-spaced; inner row of long dentary teeth, outer row mostly missing and uncountable.

This species was put in the genus Anarchias when it was thought that species of Anarchias had a long dorsal fin (found to be a fold of flesh, the fin-rays confined to the tip of the tail). It lacks the fourth supraorbital pore that defines Anarchias, and therefore belongs in Uropterygius; the species cannot be determined due to the poor condition of the holotype. Recent publications (Paxton et al., 1989: 127; Eschmeyer, 1998: 780) have misspelled the species name as "insuentus".

Fimbrinares mosaica Whitley, 1948: 72. Holotype AMS IA.3926, 1033 (1069) mm TL; Point Banks, Botany Bay, NSW, 2 m; H. Warner; 23 June 1929.

\section{= Enchelycore ramosa (Griffin, 1926)}

The holotype is large and hard, measurements taken only approximate. It is dark tan with dark brown reticulations forming large squares along body and tail, the squares patterned with small brown spots; fins similarly patterned; head with diffuse pattern. Mouth not closing completely, exposing long fang-like teeth; posterior nostril above and before eye, the inside of the nostril protruding (the tassellike fringes mentioned by Whitley which are the basis for his new genus Fimbrinares). Preanal length 2.2 in TL; VF 6-54-145. Teeth numerous, of varying sizes with many long fangs, mouth not closing completely. Intermaxillary teeth in 5 rows across, with 4 median teeth; about 2 rows of long fang-like inner maxillary teeth plus irregular outer row of shorter teeth of varying sizes; no vomerine teeth visible; 11 long inner dentary teeth, irregular outer row of teeth of varying sizes, none as large as those of inner row. This species was put in the synonymy of Enchelycore ramosa by Randall \& McCosker (1975), based on coloration and dentition.

Gymnothorax ramosus Griffin, 1926: 539, pl. 94. Holotype AIM; Whangaroa and Bay of Islands, North Auckland, New Zealand.

= valid as Enchelycore ramosa (Griffin, 1926)

We did not see the holotype or the paratype and are unaware of recent information concerning their existence. The colour 
pattern of large, spotted, polygonal spots formed by dark reticulations on head, body and fins, dorsal fin with narrow pale margin, anal fin dark basally with pale margin, is depicted on plate 94 , as is the fang-like dentition. Color photographs of live Enchelycore ramosa appear in Randall (1970: 57) and Kuiter (1993: 33). Its identity as a valid species of Enchelycore was proposed by Randall \& McCosker (1975) and followed by Paxton et al. (1989: 128).

Gymnothorax scriptus Schneider in Bloch \& Schneider, 1801: 529. Holotype ZMB (missing); New Holland, Australia.

\section{= Gymnothorax, nomen dubium}

This species was briefly described in Latin only; the type specimen could not be located at ZMB (the description stated "Kaan dictus", suggesting that no specimen existed, according to H.-J. Paepke, pers. comm., 1995). The name must be considered a nomen dubium.

\section{Miscellaneous remarks}

During the course of this study, several names have been deleted from previously published lists of Australian species (the most recent, Paxton et al., 1989) and some specimens mentioned in published accounts have been re-identified. Australian specimens identified as Gymnothorax melanospilos (Bleeker, 1855) (a junior synonym of $G$. isingteena [Richardson, 1845]) were incorrectly identified. Species that have now been determined to be junior synonyms include: Anarchias fuscus Smith, $1962=$ A. allardicei; Gymnothorax boschii $($ Bleeker, 1853) $=$ Echidna nebulosa ; and Gymnothorax wooliensis Whitley, $1968=$ G. prionodon. Four names are considered to be nomena dubia: Anarchias insuetus (usually cited as A. insuentus), Gymnothorax dakini and G. garsiae (types lost), and G. scriptus (type not extant); these species are not identifiable (Australian specimens previously identified as G. scriptus have been re-identified as G. minor). The locality of Muraena australiae Richardson, 1848, is considered to be erroneous; the type specimen is a common Mediterranean species, M. helena. In addition, four morays are here included in different genera (Echidna zebra = Gymnomuraena zebra; Siderea picta $=$ Gymnothorax pictus; Siderea thyrsoidea $=$ Gymnothorax thyrsoideus; and Uropterygius obesus $=$ Gymnothorax obesus), and the name of one species has been changed (Thyrsoidea macrura $=$ Strophidon sathete) . The wide-ranging Indo-Pacific Zebra moray, Gymnomuraena $z e b r a$, was also treated by earlier authors as Arndha zebra. And in much of the 20th century literature, many species now recognised as Gymnothorax were interchangeably placed in Lycodontis.

We have identified the specimens from Lord Howe Island identified as "Gymnothorax sp." in Allen et al. (1976: 376377) as follows: sp. A (AMS I.17456-001) is G. eurostus; sp. B (BPBM 14927) is G. atolli; and sp. C (BPBM 14786) is $G$. javanicus; the specimen identified as G. panamensis (BPBM 14945) and later described by Lavenberg (1992) as a paratype of G. australicola is G. atolli.

We have identified those photographs of morays published by Sainsbury et al. (1984: 55-57) and by Gloerfelt-Tarp \& Kailola (1984: 54-57) as follows: Gymnothorax sp. 1 is G. longinquus; Gymnothorax sp. 2 is
G. pseudothyrsoideus; Gymnothorax sp. 3 is G. mccoskeri; and their Gymnothorax reticularis is G. minor. In addition, we have identified those species listed in Sainsbury et al. on page 331 as follows: Gymnothorax sp. 4 is $G$. cephalospilus; sp. 5 is G. thyrsoideus; sp. 6 is $G$. pseudothyrsoideus; and sp. 7 is Uropterygius nagoensis.

\section{Comments on Australian/New Zealand muraenid distributions}

It is safe to assume that the majority of shallow water moray species, particularly in tropical Australian waters, have been discovered. Although most moray eels normally inhabit waters shallower than $50 \mathrm{~m}$, the junior author (unpublished data) recently observed from submersible dives in the eastern Pacific and western Atlantic that they tend to occupy considerably deeper reef habitats than previously thought. The recent discovery of new muraenid species is often because they come from habitats that are extremely difficult to sample except by deep trapping. And on that basis, we presume that the shallow water distribution data comprise the more reliable patterns of zoogeographic significance.

The widespread distribution of many anguilliform fishes is due in large part to their long larval life and the suitability of the leptocephalus to a planktonic existence. Little however is known about the duration of muraenid leptocephali. Castle (1965) estimated muraenid larval duration to be eight to ten months for those Indo-Pacific species he examined, whereas estimates of larval duration for the widely distributed western Atlantic Gymnothorax ocellatus range from six to eight months (Eldred, 1969, as G. nigromarginatus) to as few as three months (Smith, 1989). The majority of Australian morays (43 of 59 species) are broadly distributed across the northern tropical coast and widespread in the tropical Indo-Pacific. Of those, nine have crossed the eastern Pacific barrier (Rosenblatt $e$ t al., 1972) and are occasionally found at the offshore islands of Galápagos, Cocos, and Clipperton (McCosker \& Rosenblatt, 1995; McCosker \& Humann, 1996), 22 extend westward as far as the African coast (Castle \& McCosker, 1986), and 11 occur in the Red Sea (Randall \& Golani, 1995). Three species are antitropical (Gymnothorax kidako, G. minor, and G. prionodon) and G. eurostus is antiequatorial (cf. Randall, 1982) in distribution, although their taxonomy is problematic at this time. It is likely that genetic analysis will better explain those relationships.

Three species display a temperate distribution that extends eastward to Easter Island (including Anarchias seychellensis, whose identity is problematic, and Enchelycore ramosa) and one of them, Gymnothorax porphyreus, is also common along the eastern Pacific mainland to Chile and Peru (Randall \& McCosker, 1975). Close affinities between temperate Australia, New Zealand, and Chilean shorefishes are not uncommon (Mead, 1970; McCosker, 1970, 1971), however in most cases they are not conspecifics. Again, a comprehensive genetic comparison would help to clarify the level of interchange and similarity. Seven moray species have an Australia and New Zealand distribution limited to temperate waters south of $25^{\circ} \mathrm{S}$; they include Enchelycore ramosa, Gymnothorax annasona, G. austrinus, G. nubilus, G. obesus, G. porphyreus, and G. prasinus. It is curious that the only moray known to inhabit 
Tasmania is $G$. prasinus. We are uncertain as to the status of G. atolli (known from specimens of variable quality from Lord Howe Island, Japan, the northern Hawaiian archipelago, and the Red Sea) and make no firm conclusions about its taxonomic or geographic status.

Several species are endemic to Australia and New Zealand and it is likely that this is not, in most cases, an artifact of rarity in collections. (We exclude Gymnothorax austrinus, known only from the holotype.) Species known only from northern Australia include G. cephalospilus, $G$. cribroris, and G. mccoskeri. Gymnothorax woodwardi is a fairly common shallow water species known only from SW Australia (Kuiter, 1997). And finally, the southern species G. annasona (known only from Lord Howe Island and Middleton and Elizabeth reefs) and G. nubilus (known from New Zealand, Norfolk Island and the Kermadec Islands) are well represented in collections but limited in distribution.

Further collecting efforts along the NW coast of Australia as well as deep trawling and trapping throughout Australian waters will likely result in the capture of additional muraenid wonders. We look forward to those discoveries.

ACKNOWLEDGMENTS. This paper is dedicated to the late Peter H.J. Castle, best known for his work on leptocephali, but who also studied the morays of Australia and New Zealand. He provided information, insight and discussion throughout the years. He was invited to be a coauthor of this manuscript, but his participation was prevented by illness.

Many individuals have generously assisted with this study, and we particularly wish to thank M. McGrouther, D. Hoese, J. Leis, J. Paxton, S. Reader, T. Trnski and other personnel of the Australian Museum, Sydney (AMS). We also thank the following: D. Lin (CAS) for assistance with photographs, J. Mounts (CAS) for the preparation of Plates 1-2, and S. Pringle (CAS) for the preparation of Figures 6 and 7; M. Littmann (ANSP) for assistance with photographs; D. Catania, M. Hoang, T. Hoang, and J. Fong (CAS) for the preparation of radiographs and other assistance; J. Williamson for radiographs of Tasmanian specimens and W.F. Smith-Vaniz (then at ANSP) for radiographs of AMS types. Many curators and collection managers have allowed us to examine specimens in their care, including: S. Schaeffer and M. Stiasney, American Museum of Natural History (AMNH); A. Gill, O. Crimmen and A. Woolger, British Museum, Natural History (BMNH); J. Randall, L. Randall, and A. Suzumoto, Bernice P. Bishop Museum (BPBM); W. Eschmeyer and T. Iwamoto, California Academy of Sciences (CAS); A. Graham (CSIRO, Hobart); M.-L. Bauchot, G. Duhamel, and J.C. Hureau, Muséum national d'Histoire naturelle (MNHN); R. McPhee and C. Roberts, Museum of New Zealand Te Papa Tongarewa (NMNZ); E. Mikschi, Naturhistorisches Museum, Wien (NMW); S. Kullander, Stockholm Natural History Museum, (NRM); K. Hatooka, Osaka Museum of Natural History (OMNH); M. Gomon, Museum of Victoria, Melbourne (NMV); T. Kingston, Queen Victoria Museum, Launceston (QVM); M. Boeseman and M.J.P. van Oijen, Rijksmuseum van Natuurlijke Historie (RMNH); R.H. Rosenblatt, Scripps Institution of Oceanography (SIO); the staff of the National Museum of Natural History (USNM); and H.-J. Paepke, Museum für Naturkunde der Humboldt-Universität (ZMB). Several photographers have generously allowed us to use their images: J.E. Randall (BPBM); R. Kuiter (Aquatic Photographics, Australia), A. Graham (CSIRO); and J.B. Hutchins (WAM). We thank T. Iwamoto and W. Eschmeyer for advice concerning this manuscript. Much of McCosker's participation in this project was accomplished during his tenure as a visiting fellow at the Australian Museum.

\section{References}

Abbott, C.C., 1861. Description of new species of apodal fishes in the museum of the Academy of Natural Sciences of Philadelphia. Proceedings of the Academy of Natural Sciences of Philadelphia 12(1860): 475-479.

Ahl, J.N., 1789. Dissertatio de Muraena et Ophichtho. Dissertationes Academicae Upsaliae habitae sub praesidio J.P. Thunberg 3(1): 1-12.

Allen, G.R., 1985. Fishes of Western Australia. Pacific Marine Fishes Book 9. Tropical Fish Hobbyist, New Jersey. Pp. 2205-2534.

Allen, G.R., 1992. Marine Fishes of Tropical Australia and SouthEast Asia. Western Australia Museum. Pp. 292, pls. 106.

Allen, G.R., D.F. Hoese, J.R. Paxton, J.E. Randall, B.C. Russell, W.A. Starck II, F.H. Talbot \& G.P. Whitley, 1976. Annotated checklist of the fishes of Lord Howe Island. Records of the Australian Museum 30(15): 365-454.

Bauchot, M.L., M. Desoutter \& P.H.J. Castle, 1993. Catalogue critique des types de poissons du Muséum national d'Histoire naturelle. Ordres des Anguilliformes et des Saccopharyngiformes. Cybium 17(2): 91-151.

Bennett, E.T., 1832. Observations on a collection of fishes from the Mauritius, presented by Mr. Telfair, with characters of new genera and species. Proceedings of the Zoological Society of London 1: 165-169.

Bleeker, P., 1852a. Bijdrage tot de kennis der ichthiologische fauna van de Moluksche Eilanden. Visschen van Amboina en Ceram. Natuurkundig Tijdschrift voor Nederlandsch Indië 3: 229-309.

Bleeker, P., 1852b. Derde Bijdrage tot de kennis der ichthiologische fauna van Celebes. Natuurkundig Tijdschrift voor Nederlandsch Indie 3: 739-782.

Bleeker, P., 1853. Derde Bijdrage tot de kennis der ichthyologische fauna van Ceram. Natuurkundig Tijdschrift voor Nederlandsch Indie 5: 233-248.

Bleeker, P., 1855. Nalezingen op de vischfauna van Sumatra. Visschen van Lahat en Sibogha. Natuurkundig Tijdschrift voor Nederlandsch Indië 9: 257-280.

Bleeker, P., 1856. Zevende bijdrage tot de kennis der ichthyologische fauna van Ternate. Natuurkundig Tijdschrift voor Nederlandsch Indië 10: 357-386.

Bleeker, P., 1857. Tweede bijdrage tot de kennis der ichthyologische fauna van Boero. Natuurkundig Tijdschrift voor Nederlandsch Indië 13: 55-82.

Bleeker, P., 1859. Over einige vischsoorten van de zuidkustwateren van Java. Natuurkundig Tijdschrift voor Nederlandsch Indië 19: 329-352.

Bleeker, P., 1863. Notices sur une collection de poissons de la Nouvelle Hollande faite á Port-Jackson. Verslagen en Mededeelingen der Koninklijke Akademie van Wetenschappen, Afdeeling Natuurkunde 15: 442-451.

Bleeker, P., 1865. Poissons inedits Indo-Archipélagiques de l'ordre des Murénes. Nederlandsch Tijdschrift voor de Dierkunde 2: 38-54.

Bloch, M.E., \& J.G. Schneider, 1801. Systema Ichthyologiae Iconibus CX Illustratum. Berolini. Pp. 1x+584, pls. 110.

Böhlke, E.B., 1982. Vertebral formulae of type specimens of eels (Pisces: Anguilliformes). Proceedings of the Academy of Natural Sciences of Philadelphia 134: 31-49.

Böhlke, E.B., 1989. Methods and Terminology. In Fishes of the Western North Atlantic, ed. E.B. Böhlke, pp. 1-7. Sears Foundation for Marine Research, memoir 1, part 9, vol. 1, Anguilliformes and Saccopharyngiformes, pp. xvii+655.

Böhlke, E.B., 1997. Notes on the identity of elongate unpatterned Indo-Pacific morays, with description of a new species (Muraenidae, Subfamily Muraeninae). Proceedings of the Academy of Natural Sciences of Philadelphia 147: 89-109.

Böhlke, E.B., 2000. Notes on the identity of small brown, unpatterned 
Indo-Pacific moray eels, with descriptions of three new species (Anguilliformes: Muraenidae). Pacific Science 54(4): 395-416.

Böhlke, E.B., J.E. McCosker \& J.E. Böhlke, 1989. Family Muraenidae. In Fishes of the Western North Atlantic, ed. E.B. Böhlke, pp. 104-206. Sears Foundation for Marine Research, memoir 1, part 9, vol. 1, Anguilliformes and Saccopharyngiformes, pp. xvii+655.

Böhlke, E.B., J.E. McCosker \& D.G. Smith, in press. Family Muraenidae. In FAO Species Identification Guide for Fishery Purposes. The Living Marine Resources of the Western Central Pacific. Vol. 3. Batoid Fishes, Chimaeras and Bony Fishes, part 1 (Elopidae to Linophrynidae), eds. K.E. Carpenter \& V.H. Niem, pp. 1643-1657. Rome, FAO: 1397-2068.

Böhlke, E.B., \& J.E. Randall, 1999. Gymnothorax castlei, a new species of Indo-Pacific moray eel (Anguilliformes: Muraenidae). Bulletin of the Raffles Museum 47(2): 549-554.

Böhlke, E.B., \& J.E. Randall, 2000. A review of the moray eels (Anguilliformes: Muraenidae) of the Hawaiian Islands, with descriptions of two new species. Proceedings of the Academy of Natural Sciences of Philadelphia 150: 203-278, pl. I-IX.

Brock, R.E., C. Lewis \& R.C. Wass, 1979. Stability and structure of a fish community on a coral patch reef community in Hawaii. Marine Biology 54(3): 281-292.

Castle, P.H.J., 1965. Muraenid leptocephali in Australasian waters. Transactions of the Royal Society of New Zealand, Zoology 7(3): 57-84.

Castle, P.H.J., \& J.E. McCosker, 1986. Family Muraenidae. In The Sea Fishes of Southern Africa, ed. M. Smith \& P. Heemstra, pp. 165-176. Johannesburg: Macmillan Publishing Company.

Chen, H.-M., K.-T. Shao \& C.-T. Chen, 1996. A new moray eel, Gymnothorax niphostigmus, (Anguilliformes: Muraenidae) from northern and eastern Taiwan. Zoological Studies 35(1): 20-24.

Coleman, N., 1983. Australian Sea Fishes South of $30^{\circ} \mathrm{S}$. Lane Cove (Sydney): Doubleday Australia Pty. Ltd., pp. 302.

Eldred, B., 1969. Embryology and larval development of the blackedge moray, Gymnothorax nigromarginatus (Girard, 1859). Florida Department of Natural Resources Marine Research Laboratory Leaflet Series 4, 1(13), pp. 16.

Eschmeyer, W.N., (ed.), 1998. Catalog of Fishes. Special publication of the California Academy of Sciences, San Francisco, pp. 2905.

Fourmanoir, P., \& J. Rivaton, 1979. Poissons de la pente récifale externe de Nouvelle-Calédonie et des Nouvelles-Hébrides. Cahiers de l'Indo-Pacifique 1(4): 405-443.

Garman, S., 1888. On an eel from the Marshall Islands. Bulletin of the Essex Institute 20: 114-116.

Gloerfelt-Tarp, T., \& P.J. Kailola, 1984. Trawled fishes of southern Indonesia and northwestern Australia. The Australian Development Assistance Bureau, Australia, pp. 406.

Glover, C.J.M., \& K.L. Branden, 1983. Additions to the marine fish fauna of South Australia. Transactions of the Royal Society of South Australia 107(2): 134-136.

Gomon, M.F., J.C.M. Glover \& R.H. Kuiter, (eds.), 1994. The fishes of Australia's south coast. Adelaide: State Print, pp. 992, 811 figs.

Griffin, L.T., 1926. Descriptions of New Zealand fishes. Transactions and Proceedings of the New Zealand Institute 56: 538-546, pls. 93-98.

Griffin, L.T., 1927. Additions to the fish fauna of New Zealand. Transactions and Proceedings of the New Zealand Institute 58(1/2): 136-150.

Griffin, L.T., 1933. Descriptions of New Zealand fishes. Transactions and Proceedings of the New Zealand Institute 63(2): 171-177, pls. 24-25.

Guichenot, A., 1848. Fauna Chilena. Peces. In Historia fisica y politica de Chile. Vol. 2, Zoologica, ed. C. Gay. Paris, pp. 372.

Günther, A., 1867. In The Fishes of Zanzibar. Acanthopterygii, Pharynogognathi, etc., R.L. Playfair \& A.C.L.G. Günther, 1867, pp. 1-153. London: John van Voorst, pp. xiv+153, 21 pls.
Günther, A., 1870. Catalogue of the Fishes in the British Museum. Vol. 8. Catalogue of the Physostomi, Containing the Families Gymnotidae, Symbranchidae, Muraenidae, Pegasidae, and of the Lophobranchii, Plectognathi, Dipnoi, Ganoidei, Chondropterygii, Cyclostomata, Leptocardii, in the British Museum. London: Taylor and Francis, pp. i-xxv+549.

Günther, A., 1871. Report on several collections of fishes recently obtained for the British Museum. Proceedings of the Zoological Society of London 1871: 652-675.

Hamilton, F., 1822. An account of the fishes found in the river Ganges and its branches. Edinburgh: Archibald Constable and Co., pp. vii+405, 39 pls.

Hatooka, K., 1984. Uropterygius nagoensis, a new muraenid eel from Okinawa, Japan. Japanese Journal of Ichthyology 31(1): 20-22.

Hector, J., 1877. Notes on New Zealand Ichthyology. Transactions and Proceedings of the New Zealand Institute 9(62): 465-472, pls. 8-10.

Hutchins, B., 1994. A survey of the nearshore reef fish fauna of Western Australia's west and south coasts-The Leeuwin Province. Records of the Western Australian Museum, Supplement 46, pp. 66.

Jenkins, O.P., 1903. Report on collections of fishes made in the Hawaiian Islands, with descriptions of new species. Bulletin of the U.S. Fish Commission 22 (for 1902): 417-511.

Jordan, D.S., \& R.E. Richardson, 1909. A catalog of the fishes of the island of Formosa, or Taiwan, based on the collections of Dr. Hans Sauter. Memoires Carnegie Museum 4(4): 159-204, pls. 63-74.

Jordan, D.S., \& E.C. Starks, 1906. In The Fishes of Samoa, D.S. Jordan \& A. Seale, pp. 204-205. Bulletin of the Bureau of Fisheries 25(1905): 173-455, pls. 33-53.

Kaup, J.J., 1856. Catalogue of the Apodal Fish in the Collection of the British Museum. London, pp. 163, pls. 1-19.

Kuiter, R.H., 1993. Coastal Fishes of South-eastern Australia. Honolulu: University of Hawaii Press, pp. 437.

Kuiter, R.H., 1997. Guide to Sea Fishes of Australia. Sydney: New Holland, pp. 434.

Lacepède, B.G.E., 1803. Histoire naturelle des Poissons. Vol. 5. Paris, pp. 1xvii+803, 21 pls.

Lavenberg, R.J., 1992. A new moray eel (Muraenidae: Gymnothorax) from oceanic islands of the South Pacific. Pacific Science 46(1): 58-67.

Leviton, A.E., R.H. Gibbs Jr., E. Heal \& C.E. Dawson, 1985. Standards in ichthyology and herpetology: Part I. Standard symbolic codes for institutional resource collections in herpetology and ichthyology. Copeia 1985(3): 802-832.

Linnaeus, C., 1758. Systema naturae per regna tria naturae... Editio Decima, Reformata. Tom 1. Holmiae. Pp. ii+824.

McClelland, J., 1844. Apodal fishes of Bengal. Calcutta Journal of Natural History 5(18): 151-226.

McCosker, J.E., 1970. A review of the eel genera Leptenchelys and Muraenichthys, with the description of a new genus, Schismorhynchus, and a new species, Muraenichthys chilensis. Pacific Science 24: 505-516.

McCosker, J.E., 1971. A new species of Parapercis (Pisces: Mugiloididae) from the Juan Fernandez Islands. Copeia 1971: 682-686.

McCosker, J.E., K. Hatooka, K. Sasaki \& J.T. Moyer, 1984. Japanese moray eels of the genus Uropterygius. Japanese Journal of Ichthyology 31(3): 261-267.

McCosker, J.E., \& P. Humann, 1996. New records of Galápagos fishes. Noticias de Galápagos 56: 18-22.

McCosker, J.E., \& J.E. Randall, 1982. Synonymies of Indian Ocean eels, with the description of Gymnothorax enigmaticus, a moray previously known as $G$. ruppeli. Proceedings of the California Academy of Sciences 43(2): 17-24.

McCosker, J.E., \& R.H. Rosenblatt, 1995. Muraenidae. In Guia FAO para la identification de especies para los fines de la 
pesca. Pacifico centro-oriental, eds. W. Fischer et al., pp. 13031314. Rome: FAO, vol. III.

McCulloch, A.R., 1912. Notes on some Western Australian fishes. Records of the Western Australian Museum 1(2): 78-97, pl. 9-13.

Mead, G.W., 1970. A History of South Pacific Fishes. Scientific Exploration of the South Pacific. Washington, D.C.: National Academy of Sciences, pp. 236-251.

Munro, I.S.R., 1957. Handbook of Australian fishes. No. 12, family Muraenidae. (Australian) Fisheries Newsletter 16(6): 49-52.

Myers, R.F., 1999. Micronesian Reef Fishes, 3rd edition. Guam: Coral Graphics, pp. 330, 192 pls.

Ogilby, J.D., 1895. Description of a new Australian eel. Proceedings of the Linnean Society of New South Wales ser. 2 (for 1894) 9: 720-721.

Ogilby, J.D., 1907. Symbranchiate and apodal fishes new to Australia. Proceedings of the Royal Society of Queensland 20: 1-15.

Paxton, J.R., D.F. Hoese, G.R. Allen \& J.E. Hanley, 1989. Zoological Catalogue of Australia. Vol. 7, Pisces, Petromyzontidae to Carangidae. Canberra: Australian Government Publishing Service, pp. viii+665.

Pietschmann, V., 1935. Eine neue Aalfamilie aus den hawaiischen Gesässern. Anzeiger der Akademie der Wissenschaften in Wien 72(11): 93-94.

Quoy, J.R.C., \& P. Gaimard, 1824. Description des Poissons: Remarques sur quelques poissons de mer. Chapter IX. In Voyage autour du monde... exécuté sur les corvettes de S.M. l'Uranie et la Physicienne, pendant les années 1817, 1818, 1819 et 1820, vol. 3, Zoologie, L. de Freycinet. Paris: Pillet Aîné, pp. 183-401, pls. 96. (1-328 in 1824, 329-616 in 1825). Atlas pls. 43-65.

Randall, J.E., 1970. Easter Island: an ichthyological expedition. Oceans 3(3): 48-59.

Randall, J.E., 1982. Examples of antitropical and antiequatorial distribution of Indo-West-Pacific fishes. Pacific Science 35(3): 197-209.

Randall, J.E., G.R. Allen \& R.C. Steene, 1997. Fishes of the Great Barrier Reef and Coral Sea, 2nd edition. Australia: Crawford House Publishing, Australia, pp. 557.

Randall, J.E., \& D. Golani, 1995. Review of the moray eels (Anguilliformes: Muraenidae) of the Red Sea. Bulletin of Marine Science 56(3): 849-880.

Randall, J.E., \& J.E. McCosker, 1975. The eels of Easter Island with a description of a new moray. Natural History Museum of Los Angeles County Contributions in Science 264, pp. 32.

Rendahl, H., 1921. The fishes of Easter Island. In The Natural History of Juan Fernandez and Easter Island, vol. 3, Zoology (1): part 1, C. Skottsberg, pp. 59-68. Uppsala: Almquist \& Wiksells, pp. 688.

Richardson, J., 1845 (1844-1845). Ichthyology. In The zoology of the voyage of H.M.S. Sulphur, under the command of Captain Sir Edward Belcher, R.N., C.B., F.R.G.S., etc. during the years 1836-42, ed. R.B. Hinds. London: Smith, Elder and Co., pp. 51-150, pls. 35-64. (Pp. 51-86 published 1844; pp. 87-150, 1845.)

Richardson, J., 1848 (1844-1848). Ichthyology of the voyage of H.M.S. Erebus \& Terror... In The zoology of the voyage of H.M.S. Erebus \& Terror, under the command of Captain Sir J.C. Ross... during... 1839-43, ed. J. Richardson \& J.E. Gray. London, Vol. 2(2): i-viii+1-139, pls. 1-60. (Pp. 1-16, 1844; 17-52, 1845; 53-74, 1846; i-viii+75-139, 1848.)

Rosenblatt, R.H., J.E. McCosker \& I. Rubinoff. 1972. Indo-west Pacific fishes from the Gulf of Chiriqui, Panama. Los Angeles County Museum of Natural History Contributions in Science, 234, pp. 18.

Rüppell, W.P.E.S., 1830 (1828-1830). Fische des Rothen Meeres. In Atlas zu der Reise im nördlichen Afrika von Eduard Rüppell. Vol. 1. Zoologie. Frankfurt am Main, pp. 144, pls. 1-35.

Rüppell, W.P.E.S., 1838 (1835-1838). Fische des Rothen Meeres. Neue Wirbelthiere zu der Fauna von Abyssinien gehörig. Frankfurt-am-Main, pp. 148, pls. 1-33.
Sainsbury, K.J., P.J. Kailola \& G.G. Leyland, 1984. Continental shelf fishes of northern and north-western Australia; An illustrated guide. CSIRO Division of Fisheries Research, Canberra, Australia, pp. viii +375 .

Sauvage, H.E., 1883. Description de quelques poissons de la collection du Muséum d'Histoire naturelle. Bulletin de la Société Philomathique de Paris ser. 7, 7: 156-161.

Schultz, L.P., 1943. Fishes of the Phoenix and Samoan Islands collected in 1939 during the expedition of the U.S.S. "Bushnell". United States National Museum Bulletin 180, pp. $\mathrm{i}-\mathrm{x}+316$

Schultz, L.P., \& collaborators, 1953. Fishes of the Marshall and Marianas Islands. Vol. 1. Families from Asymmetrontidae through Siganidae. United States National Museum Bulletin 202, pp. i-xxxii+685.

Scott, E.O.G., 1965. Observations on some Tasmanian fishes. Part 13. Papers and Proceedings of the Royal Society of Tasmania 99: 53-65, fig. 1.

Seale, A., 1906. Fishes of the South Pacific. Occasional Papers of the Bernice P. Bishop Museum 4(1): 1-89.

Shaw, G., in Shaw, G., \& F.P. Nodder, 1795. Naturalist's Miscellany, vol. 7. London: F.P. Nodder \& Co. Unnumbered pp. + pls. 219-254.

Shaw, G., in Shaw, G., \& F.P. Nodder, 1797. Naturalist's Miscellany, vol. 9. London: F.P. Nodder \& Co. Unnumbered pp. + pls. 301-348.

Smith, D.G., 1989. Family Muraenidae: Leptocephali. In Fishes of the Western North Atlantic, ed. E.B. Böhlke, pp. 900-916. Sears Foundation for Marine Research, memoir 1, part 9, vol. 2, Leptocephali, pp. vii+657-1055.

Smith, D.G., \& E.B. Böhlke, 1997. A review of the Indo-Pacific banded morays of the Gymnothorax reticularis group, with descriptions of three new species (Pisces, Anguilliformes, Muraenidae). Proceedings of the Academy of Natural Sciences of Philadelphia 148: 177-188.

Smith, J.L.B., 1962. The moray eels of the western Indian Ocean and the Red Sea. Rhodes University Ichthyological Bulletin 23: 419-444.

Snyder, J.O., 1904. A catalogue of the shore fishes collected by the steamer "Albatross" about the Hawaiian Islands in 1902. United States Bureau of Fisheries Bulletin 22: 513-538.

Steindachner, F., 1866. Zur Fischfauna von Port Jackson in Australien. Sitzungsberichte der Kaiserlichen Akademie der Wissenschaften Mathematisch-Naturwissenschaftliche Classe 53: 424-481, pls. 1-7.

Steindachner, F., 1896. Bericht über di während der Reise Sr. Maj. Schiff "Aurora" von Dr. C. Ritter v. Mieroszewski in den Jahren 1895 und 1896 gesammelten Fische. Annalen des K.K. Naturhistorischen Hofmuseums 11(2): 197-230, pl. 4.

Tanaka, S., 1918. Nihon san gyorui no ni shinshu (Two new species of fishes from Japan). Dobutsugaku Zasshi (Zoological Magazine) 30: 51-52.

Tanaka, S., 1931. On the distribution of fishes in Japanese waters. Journal of the Faculty of Science, Imperial University of Tokyo, sec. 4, Zoology 3(1): 1-90, pls. 1-3.

Temminck, C.J., \& H. Schlegel, 1846 (1842-1850). Pisces. In: Fauna Japonica, sive descriptio animalium que in itinere per Japoniam suscepto annis 1823-30 collegit, notis observationibus et adumbrationibus illustravit P.F. de Siebold. Parts 1-20. Leiden. pp. 345, pls. 144. (Pp. 1-20, 1842; 21-72, 1843; 73112,$1844 ; 113-172,1845 ; 173-269,1846 ; 270-324,1850$.)

Waite, E.F., 1904. Additions to the fish-fauna of Lord Howe Island, no. 4. Records of the Australian Museum 5(3): 135-186, pls. 17-24, figs. 32.

Weber, M., \& de Beaufort, L.F., 1916. The fishes of the IndoAustralian Archipelago. 3. Ostariophysi II Cyprinoidea, Apodes, Synbranchi. Leiden: Brill, pp. 455, figs. 214. 
Whitley, G.P., 1931. New names for Australian Fishes. Australian Zoologist 6(4): 310-334, pls. 25-27.

Whitley, G.P., 1932a. Studies in ichthyology, no. 6. Records of the Australian Museum 18(6): 321-348, pls. 36-39.

Whitley, G.P., 1932b. Fishes. Scientific Report of Great Barrier Reef Expedition 4(9): 267-316, pls. 1-4.

Whitley, G.P., 1934. Studies in ichthyology, no. 8. Records of the Australian Museum 19(2): 153-163.

Whitley, G.P., 1937. The Middleton and Elizabeth Reefs, South Pacific Ocean. Fishes. Pp. 214-231. Australian Zoologist 8(4): 199-273, pls. 13-17.

Whitley, G.P., 1948. Studies in ichthyology, no. 13. Records of the Australian Museum 22(1): 70-94, figs. 1-11.
Whitley, G.P., 1968. Some fishes from New South Wales. Proceedings of the Royal Zoological Society of New South Wales 1966-67: 32-40, 3 figs., 2 pls.

Whitley, G.P., \& A.N. Colefax, 1938. Fishes from Nauru, Gilbert Islands, Oceania. Proceedings of the Linnean Society of New South Wales 63(3-4), nos. 277-278: 282-307, pl. 14, 3 text-figs.

Whitley, G.P., \& W.J. Phillipps, 1939. Descriptive notes on some New Zealand Fishes. Transactions and Proceedings of the Royal Society of New Zealand 69(2): 228-236, pls. 21-22.

Manuscript received 23 June 2000, revised 2 October 2000 and accepted 17 October 2000.

Associate Editor: J.M. Leis.

\section{Index}

afra, Muraena...... allardicei, Anarchias ........ 73, 75, 98 Anarchias .............................. 72, 74, 75, 97 annasona, Gymno. .. 72-74, 82, 83, 84, 98, 99 atolli, Gymno. ......... 72-74, 79, 84, 85, 98, 99 atolli, Heteromyrus ........................... 84, 85 australiae, Muraena ….............................. 98 australicola, Gymnothorax ........... 84, 85, 98 austrinus, Gymno. .. 72, 73, 79, 85, 88, 98, 99 bayeri, Enchelycore ........................... 73, 77 boschii, Gymnothorax ……………................ 98 buroensis, Gymnothorax ..................... 73, 79 callorhyncha, Muraena ......................... 93, 94 callorhyncha, Notorabula ...........................93 cancellata, Muraena ......................................96 canina, Enchelynassa .......................... 73, 77 cantonensis, Anarchias .......................... 73-75 castaneus, Gymnothorax ................................... 94 castlei, Gymnothorax .............. 73, 74, 77, 90 cephalospilus, G. .... 72, 73, 80, 86, 88, 98, 99 chalazius, Gymnothorax .............................97 chilensis, Muraena ......................................... 92 chilospilus, Gymnothorax .................... 73, 82 concolor, Uropterygius ....................... 73, 75 cribroris, Gymno. ......... 72, 73, 82, 87, 88, 99 dakini, Gymnothorax .......................... 97, 98 Echidna ............................................. 72, 76 elegantissima, Muraena .............................. 97 Enchelycore …………………...... 72, 77, 98 Enchelynassa .......................................... 72 enigmaticus, Gymnothorax ............. 73, 74, 78 euptera, Muraena ................................. 90, 91 eurostus, Gymnothorax ........... 73, 79, 97, 98 favagineus, Gymnothorax .................... 73, 81 fimbriatus, Gymnothorax .................... 73, 81

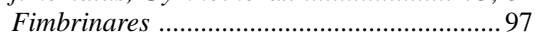
flavimarginatus, Gymno. .... 73, 81, 84, 92, 97 flavimarginatus annasona, G. ............ 83, 84 funebris, Gymnothorax ................................ 94 fuscoguttatus, Uropterygius .................. 73, 76 fuscomaculatus, Gymnothorax .............. 73, 77 fuscus, Anarchias ........................................... 98 garsiae, Gymnothorax .......................... 97, 98 gracilicaudus, Gymnothorax............... 73, 82 griffini, Gymnothorax ......................... 91, 92 griseus, Gymnothorax .................................... 90 Gymnomuraena …….................................... 72 Gymnothorax ............... 72, 77, 83, 94, 97, 98 helena, Muraena ………………….... 96, 98 helena australiae, Muraena ........................... 96 insuentus, Anarchias ........................... 97, 98 insuetus, Anarchias .................................. 97, 98 intesi, Gymnothorax ............................ 73, 80 isingteena, Gymnothorax ................................. 98 jacksoniensis, Gymnothorax ................ 93, 94 javanicus, Gymnothorax ............... 73, 81, 98 johnsoni, Lycodontis .................................... 95 kidako, Gymnothorax .............. 73, 80, 95, 98 krulli, Muraena ..................................... 93, 94

leecote, Gymnothorax ......................... 93, 94 leucostigma, Gymnothorax ......................94-96 leucurus, Anarchias ..............................73-75 longinquus, Gymnothorax .. 72, 73, 80, 88, 98 longinquus, Lycodontis ....................... 88, 89

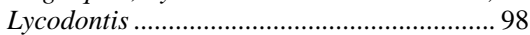
macrura, Thyrsoidea ...................................... 98 maculaepinnis, Gymnothorax .............. 93, 94 margaritophorus, Gymnothorax .... 73, 82, 88 marmoratus, Uropterygius .................. 73, 76 mccoskeri, Gymnothorax ... 73, 74, 78, 98, 99 melanospilos, Gymnothorax .........................98 melatremus, Gymnothorax ……..................... 73, 77 meleagris, Gymnothorax ............... 73, 79, 91 micropterus, Uropterygius ................... 73, 76 mieroszewskii, Gymnothorax ....................... 95 mieroszewskii, Muraena .......................94-96 minor, Gymnothorax …............. 73, 74, 78, 98 monochrous, Gymnothorax ................. 73, 78 mosaica, Fimbrinares .....................................97 nagoensis, Uropterygius................ 73, 76, 98 nebulosa, Echidna ........................ 73, 76, 98 nigromarginatus, Gymnothorax .................. 98 niphostigmus, Gymnothorax ........................ 95 nirosus, Gymnothorax .......................... 94, 95 Notorabula … nubila, Muraena ...................................... 90, 91 nubilus, Gymno. .......72, 73, 82, 90, 91, 98, 99 nudivomer, Gymnothorax .................... 73, 80 obesus, Gymno........ 72, 73, 80, 88, 91, 92, 98 obesus, Uropterygius …............ 88, 91, 92, 98 obscurirostris, Gymnothorax ....................... 92 ocellatus, Gymnothorax ............................. 98 panamensis, Gymnothorax ........................... 98 parini, Gymnothorax …….................... 84, 92 pavonina, Muraena ........................................ 96

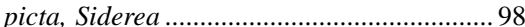
pictus, Gymnothorax ................ 73, 82, 97, 98 pindae, Gymnothorax .......................... 73, 79 polyuranodon, Gymnothorax .............. 73, 81 polyzona, Echidna ……....................... 73, 76 polyzona, Muraena ……............................ 96 porphyreus, Gymno. ...... 72-74, 81, 92, 93, 98 porphyreus, Muraena .................................. 92 porphyreus, Muraenophis ................................. 92 prasina, Muraena .............................. 93,94 prasinus, G.. 72, 73, 78, 85, 89, 93, 94, 98, 99 prasinus, Verdithorax ................................. 93 prionodon, $G \ldots \ldots \ldots . . .72,73,80,89$, 94-96, 98 prionodon, Serranguilla .............................. 95 pseudoherrei, Gymnothorax ........... 73, 74, 78 pseudothyrsoideus, Gymnothorax.. 73, 82, 98 quaesita, Rhinomuraena ...................... 73, 77

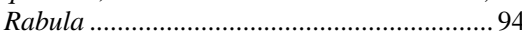
ramosa, Enchelycore ............... 73, 77, 97, 98 ramosus, Gymnothorax ................................ 97 reticularis, Gymnothorax ............................. 98 rueppelliae, Gymnothorax .................. 73, 78 sathete, Strophidon …..................... 73, 77, 98 scriptus, Gymnothorax ......................... 74, 98 Scuticaria ................................................... 72

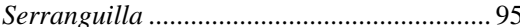
seychellensis, Anarchias ................. 73, 75, 98 shirleyi, Muraena ............................... 94, 95 sp. 1, Gymnothorax …………….......... 88, 98 sp. 2, Gymnothorax …………………........... 98 sp. 3, Gymnothorax ……………………...... 98 sp. 4, Gymnothorax ………………....... 86, 98 sp. 5, Gymnothorax ……............................ 98 sp. 6, Gymnothorax ....................................... 98 sp. 7, Gymnothorax …............................... 98 sp. A, Gymnothorax ….......................... 84, 98 sp. B, Gymnothorax ………………………... 98 sp. C, Gymnothorax ……………………........ 98 Strophidon ....................................................... 72 thyrsoidea, Siderea ......................................98 thyrsoideus, Gymnothorax .............. 73, 77, 98 tuhua, Muraena …….............................. 91 undulatus, Gymnothorax ................ 73, 81, 96 unicolor, Echidna .............................. 73, 76 Uropterygius ............... 72, 74, 75, 81, 91, 97

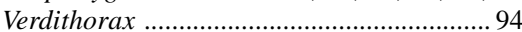

Wieneri, Gymnothorax ........................ 92, 93 woodwardi, Gymno. ....... 72, 73, 80, 89, 96, 99 wooliensis, Gymnothorax .................... 95, 98 wooliensis, Lycodontis ...........................94-96 zebra, Arndha ............................................ 98 zebra, Echidna .............................................. 98 zebra, Gymnomuraena ................... 73, 76, 98 zonipectis, Gymnothorax ..................... 73, 82 